\title{
Some patterns of interaction between science and policy: Germany and climate change
}

\author{
Dennis Bray ${ }^{1, *}$, Carsten Krück ${ }^{2}$ \\ ${ }^{1}$ GKSS Forschungszentrum, Max-Planck Strasse, 21502 Geesthacht, Germany \\ ${ }^{2}$ VDI-Technologiezentrum, Abteilung Zünftige Technologein, 40002 Düsseldorf, Germany
}

\begin{abstract}
The issue of climate change from the perspectives of climate change scientists and climate policy makers is discussed using results from 2 survey questionnaires. Emphasis is given to the German context. Included is the self assessment of the state of the art of the climate sciences and the importance assigned to different sources of information by policy makers. Conclusions indicate that policy makers rely on a number of sources other than the direct results of science, and have assigned a greater sense of urgency to the issue of climate change than have scientists; therefore it might be that some aspects of climate science are being driven by the normative judgements of a political perspective.
\end{abstract}

KEY WORDS: Climate change $\cdot$ Climate change policy $\cdot$ Scientific consensus $\cdot$ Science-to-policy relationships $\cdot$ Normative driven science

Resale or republication not permitted without written consent of the publisher

\section{INTRODUCTION}

This paper attempts to provide an empirical example of the relationships between the production of scientific knowledge and the production of related policy using climate science to represent 'science' and the German non-elected government officials, the 'Exekutive', charged with devising climate change policy to represent 'policy'. Using these categories this paper will explore the relationships as they exist between knowledge production and organization, dissemination and application in the policy realm. It will do so within the context of global warming, the German climate science community and the German Exekutive charged with formulating climate change related policy. Exekutive refers to non-elected civil servants, in this case, those civil servants whose duties include the formulation of climate change related policy. Ultimately, we explore the possibilities that science, perhaps in part, is being driven by politics, and that policy is not always driven by the best efforts of science. While this is often discussed and deliberated, we attempt to provide a concrete quantitative empirical example.

*E-mail: bray@gkss.de
The example will employ the results of 2 surveys, one of climate scientists (so as to locate the German climate science community in a broader international context) and one of the German Exekutive (so as to explore the relationship between science and policy). Measures of consensus are assessed within climate scientists as a national groupings, the German Exekutive and the IPCC. The section on the dissemination of knowledge addresses the relationships from the perspectives of both the disseminator and the receiver in the context of multiple channels, for example, IPCC to Exekutive, direct from science personalities to the Exekutive and from external sources such as the media or other government commissions to those charged with policy formation. ${ }^{1}$

\footnotetext{
${ }^{1}$ While many science-technology studies might suggest the following is a naive conception of the process of the transfer of knowledge, we can only represent what is evident in the data and lay no claim to knowledge of the motives and psychology of individual scientists, newspaper editors, policy makers, etc. Neither do we intend to reify science, believing instead that any conspiracy theory is somewhat devoid of reality and any consequences of science are the result of the action of individuals, not necessarily the unified effort of a collective body
} 
The nature of the climate change issue is also such that it needs a brief discussion. The issue of global climate change presents itself as somewhat of an exemplar in the fact that it encompasses the characteristics of post-normal science, that is, science conducted in the context of potentially high stakes and with a high degree of uncertainty (see Funtowicz \& Ravetz 1985, 1990a,b, Bray \& von Storch 1999a). It is also an exemplar in that it is representative of what perhaps could be called 'encroaching post-normal problems'; that is, the issue is a problem in the sense that it exercises the mind, but it is not normal if normal is perceived of as something which conforms to a standard or regularity, or that which is usual or typical. The issue of global climate change has now extended well beyond those conditions. 'Normal' would imply at least the existence of a precedent. Consequently, the resolution to climate change within our current level of understanding extends beyond a scientific understanding of the natural world to include the interpretation of identified risks, the ways the risks might be negotiated, and the consideration of unforeseen consequences. While the necessity of such considerations is not new, the realization of this necessity is distinguishing and the interaction of scientists, policy makers, journalists, ethics, technologies, and cultural definitions cannot be ignored. Such an interaction, to be successful, requires intricate patterns of communication. This is interaction in which, firstly, scientific expert knowledge must be transformed into a more general context of practical, pragmatic knowledge, and secondly, the knowledge must be communicated and utilized.

From the constructivist-relativist point of view now prominent in much of sociology, knowledge is perceived of as being socially connected and socially constructed. In short, it is a social artifact that is contextually and historically situated. And, it is, after all, in society where impacts and patterns of adaptation will be played out, for concern seems ultimately to be with human well-being, despite the fact that well-being is often couched in economic terms. If the issue of change in the natural world poses a real threat, then an extreme constructivist position provides little in the way of providing pragmatic information. In contrast, the positivist-realist position held by many natural scientists holds that the world has its own effective reality, and employed to the extreme, such an approach results in naive determinism. It is from these extremes that policy makers must draw conclusions. The reality of post-normal problems demands the perhaps moderated inclusion of both relativist and realist views, and the lines of communication need to be open and clear. Unfortunately this is rarely the case. Consequently, decision makers are left with somewhat of a piecemeal approach to decision making. This provides the oppor- tunity for poor science to inform policy and for misinformed politics to feed back into science. The following does not attempt to provide a solution to these problems but rather to exemplify some problem areas.

\section{THE SURVEY OF SCIENTISTS}

The survey of climate scientists (conducted by D. Bray \& H. von Storch in 1996) began with a series of indepth interviews conducted with climate scientists located in major institutions in the USA, Germany and Canada. A list of pertinent themes was abstracted from the interviews and used to construct a survey questionnaire. In 1996, the questionnaire was distributed to 1000 scientists in North America and Germany. An early publication drew requests to include other national science communities and subsequently, in 1997, Denmark and Italy were added to the data set.

The sample for the North American segment was drawn from the 'EarthQuest' mailing list. Due to the fact that the mailing list contained people other than climate scientists, a true random sample could not be drawn. A final sample size for North America of 460 US scientists and 40 Canadian scientists was selected. The sampling of the German science community, due to reasons of confidentiality, was beyond full control. A random sample of German scientists was drawn from the mailing list of the 'Deutsche Meteorologische Gesellschaft' by its administration, resulting in the distribution of 450 surveys. A further 50 questionnaires were distributed to the members of the Max-PlanckInstitut für Meteorologie, Hamburg, and members of the University of Hamburg. The Danish sample was drawn from the membership of the Danish Meteorological Society, by the Danish Meteorological Society, and consisted of a random sample of 100, and the Italian sample of 240 was drawn from lists of members of related academic departments by a member of the Italian academic community. ${ }^{2}$ Final response rates are given in Table $1 .^{3}$

While the selection of countries is representative of a variety of vested national interest, both economic and environmental, it is limited in representing only Western industrialized nations. ${ }^{4}$ Nonetheless, the geographical vastness of North America means a number of climatic zones and long coastlines to deal with, both

\footnotetext{
${ }^{2}$ Thanks are due to Paolo Battinelli of the Osservatorio Astronomico di Roma for the selection of the sample and his contribution to the subsequent compilation of the report in Battinelli et al. (1999)

${ }^{3}$ Other results from the survey include: Bray \& von Storch (1997a,b, 1999a,b), Battinelli et al. (1999), von Storch \& Bray (1999) and von Storch et al. (1999)
} 
Table 1. Response rates to survey

\begin{tabular}{|lcc|}
\hline Country & Mailed out & Returned \\
\hline USA & 460 & 149 \\
Canada & 40 & 35 \\
Germany & 500 & 228 \\
Italy & 240 & 73 \\
Denmark & 100 & 28 \\
\hline
\end{tabular}

for science and for politics. Germany, on the other hand, is somewhat more geographically and climatically homogeneous. Both Denmark and Italy face increased risk of rising sea levels. In short, the selection of countries is representative of a diversity of interests regarding the physical impacts of climate change. They are however somewhat homogeneous in terms of economic design, that is, at an economic level of analysis, goals would be expected to be more similar than different. Furthermore, all scientific communities in the study share the same Judeo-Christian roots of the development of science.

\section{THE SURVEY OF THE GERMAN EXEKUTIVE}

The survey of the German Exekutive (conducted by C. Krück \& D. Bray in 1998), rather than drawing a sample, addressed the entire population of relevant German policy making departments at the 'Bund' (federal) level and the 'Länder' (province/state) level. The ministries included research, environment, transport, housing, economics, finance, agriculture, etc. Relevancy for inclusion in the survey was determined by the use of official organizational charts listing the divisions, groups and departments in each ministry. The charts noted the heads of departments and provided a short description of the department's portfolio. A questionnaire was sent to each person whose portfolio included climate and environmental protection in general. Additionally, official address lists such as the list of German delegates to the FCCC and the list of members on the Interministerial Working Group on $\mathrm{CO}_{2}$ Reduction were included. The total mail out to members at the Bund level was 118. The response was the return of 27 completed questionnaires. This seemingly

\footnotetext{
${ }^{4}$ An attempt was made to make optimal use of resources. Further resources would provide the possibility to include lesser developed countries. However, when addressed according to national origin, the results for the countries included in the sample would remain unchanged. What might change is general statements referring to the perspectives regarding the 'scientific community' and respective patterns of interaction with policy makers and the media in respective national contexts
}

low response rate is likely influenced by the fact that in some ministries the survey was simply passed on from subordinates to superiors, resulting in one survey representing the view of the entire department. At the Länder level, 399 surveys were distributed and 120 completed surveys were returned. Table 2 indicates the breadth of the interests of the respondents. Multiple roles of the respondents is also a possibility. In short, the duties of the Exekutive are well integrated into other economic and social concerns. That is, concerns are multiple in most cases.

\section{KNOWLEDGE AND INFORMATION}

Information is what is produced by science when these facts extend beyond scientific discussion. That is, scientific facts are knowledge within the contexts of 'scientific' discussion but are little more than information once they leave the confines of the scientific context and scientific expertise. For policy makers, scientific knowledge might simply represent confusing information. What is necessary in this case is the transformation of scientific knowledge to knowledge of a kind that can be employed in the practical design and implementation of policy.

Knowledge then is the substance of the relationships to be discussed, therefore it is necessary to present a brief operational definition and the context in which it will be employed in this paper. The Oxford English Dictionary (1993) define the verb 'to know' as 'recognize, perceive, identify [...] to comprehend as fact or truth'. In short, knowledge extends beyond the mere

Table 2. Respondents from the German Exekutive

\begin{tabular}{|lr|}
\hline Duties & No. of respondents \\
\hline Environmental protection/ecology & 45 \\
Specifically climate change & 19 \\
Energy/energy politics/energy conservation & 15 \\
Economics & 13 \\
Traffic & 11 \\
Research/science/technological transfer & 10 \\
Forest protection/forest economics/forest ecology & 9 \\
Agricultural economics/agricultural politics & 6 \\
Water protection/water economics & 3 \\
Regional planning/land development & 5 \\
Structural politics/major principles/framework & 3 \\
Coastal protection & 2 \\
Building/construction & 2 \\
Soil protection & 2 \\
Waste/rubbish & 1 \\
Health & 1 \\
Finance & 1 \\
Emission protection & 1 \\
Not disclosed & 5 \\
\hline
\end{tabular}


collection of data and information. The transformation of data or information into knowledge implies the application of subjective assessment. ${ }^{5}$ The IPCC is one central organization that has been charged with the responsibility to make comprehensive sense of the scientific knowledge concerning climate change and transform it into a more digestible state for the purposes of policy making. The metaphor of a silo adequately describes the purpose of the IPCC, namely for the transformation, storage and dissemination of knowledge. A silo is typically a chamber used for storing grain, roots, etc., in which green crops are compressed and preserved for fodder as silage. The IPCC typically 'compresses' knowledge and uncertainty into a consensual depiction of the state of the science. The compression is even more so if one considers the executive summary for the use of policy makers, where the compressed knowledge then becomes the fodder for the next round of international negotiations regarding climate change. In short, the fodder is the transformed scientific knowledge intended for the gullet of the policy maker. (It is not the objective here however, to discuss the internal process of IPCC deliberations and it should be kept in mind that the IPCC is but one source of information/knowledge for policy makers, but is often the referral point in international debate.) In general, the utility of such silos might be assessed by their ability to act as a stimulus for the process of knowledge building, in which reason and the perceptions of rationality become forces of the transition of scientific knowledge to knowledge with a broader use value.

\section{LOCATING GERMAN SCIENCE IN AN INTERNATIONAL SETTING}

Arrow et al. (1996, p. 62) note that decisions regarding issues of climate change have the distinction of not being the result of a single decision maker. Each decision maker comes with a set of objectives and values that provide a different base, hindering, if not preventing, a single universally preferred solution. We can assume that political perspectives, as influenced both by measures of international scientific consensus and

\footnotetext{
${ }^{5}$ The difficulty is well noted: 'Information scientists are currently confronted with the need to distinguish information gathering from knowledge building. For example, criticism of the World Wide Web stems from a lack of knowledge structure in the unorganized information system. User frustration with the system is due to an inability to determine truth from falsehood, to build the proper context around information to make it usable, to make sense of it' Glynn \& Laskaris: http://hsb.baylor.edu/ramsower/ais.ac.96/papers/ glynn.htm. As a metaphor, this can be applied to the issue and related uncertainties of global climate change
}

national peculiarities, are the most influential in devising international policy. However, we would expect some representation of unity among the various scientific communities, differing perhaps more on their respective interfaces with policy makers and their 'extended' knowledge claims than on the 'facts' of the science. (By extended knowledge claims we mean areas beyond the scientific expertise of the scientists involved.) Represented at the international bargaining table, then, are singular 'national' perspectives. International negotiations, we assume are guided somewhat by scientific perspectives and if results to date are indicative, political perspectives differ considerably in some cases (more so if one considers recent statements from US politics), consequently suggesting that the perspectives of the scientific community, if the results of science are effective, also differ. This would also be an indication that such collective efforts such as that by the IPCC might be undermined by national level scientific input. Furthermore, within national boundaries, where policy implementation has so far been more successful, there remains, at the level of policy development, the distinction between regional and national politics, which, while drawing ultimately from the same scientific sources, have a variety of different concerns regarding the design and implementation of policy.

One more note is necessary here regarding the representation of the data. We do not necessarily adhere to the current and recent past trend of typical Science, Technology and Society (STS) studies that seem to have reified science, forgetting that it is made up of individuals. Using a number of methodologies STS studies have attempted to demonstrate that the idealist image of science is simply a legitimizing veneer hiding science's true institutional self interests, which could be assumed from the literature to be power, status and self preservation. To restate, we prefer to refer to scientists, not science. As in any enterprise, it would be extremely naive to assume that within the structures of science there are not those individuals prone to self interest and entrepreneurial spirit. In this sense we do not feel that science as an enterprise differs from most enterprises. When referring to the science of climate change, we present our data as box plots representing the responses of the sample of scientists questioned. ${ }^{6}$ Outliers and extreme values are included to retain the 'individuality' that exists within the scientific community.

In this section, some areas of contention and consensus within the scientific communities are explored. This is the shape of the knowledge presented to the policy makers. Quite simply, scientists were asked to assess the ability of atmospheric climate models to deal with the processes of hydrodynamics, radiation, 
Table 3. Statistically significant differences $\left({ }^{*}\right)$ for consensus, using a Student-Newman-Keuls test with a significance level set at 0.05. Ita: Italy, Can: Canada, Ger: Germany, USA: United States of America, Den: Denmark

\begin{tabular}{|c|c|c|c|c|c|c|}
\hline \multicolumn{2}{|c|}{$\begin{array}{l}\text { Mean Variable } \\
1=\text { very inadequate } \\
7=\text { very adequate }\end{array}$} & \multirow[t]{2}{*}{ Ita } & \multirow[t]{2}{*}{ Can } & Ger & \multicolumn{2}{|c|}{ USA Der } \\
\hline & Hydrodynamics & & & & & \\
\hline 3.88 & Italy & & & * & $*$ & * \\
\hline 4.37 & Canada & & & & & \\
\hline 4.72 & Germany & & & & & \\
\hline 4.74 & USA & & & & & \\
\hline \multirow[t]{2}{*}{5.06} & Denmark & & & & & \\
\hline & Radiation & & & & & \\
\hline 4.42 & Italy & & & & & \\
\hline 4.63 & Canada & & & & & \\
\hline 4.70 & Germany & & & & & \\
\hline 4.55 & USA & & & & & \\
\hline \multirow[t]{2}{*}{4.73} & Denmark & & & & & \\
\hline & Clouds & & & & & \\
\hline 3.95 & Italy & & * & * & $*$ & * \\
\hline 2.71 & Canada & & & & & \\
\hline 3.14 & Germany & & & & * & * \\
\hline 2.66 & USA & & & & & \\
\hline \multirow[t]{2}{*}{2.27} & Denmark & & & & & \\
\hline & Precipitation & & & & & \\
\hline 3.82 & Italy & & * & * & $*$ & $*$ \\
\hline 2.86 & Canada & & & & & \\
\hline 3.17 & Germany & & & & & \\
\hline 2.81 & USA & & & & & \\
\hline \multirow[t]{2}{*}{2.97} & Denmark & & & & & \\
\hline & Convection & & & & & \\
\hline 3.89 & Italy & & & & * & \\
\hline 3.46 & Canada & & & & & \\
\hline 3.63 & Germany & & & & & \\
\hline 3.28 & USA & & & & & \\
\hline 3.53 & Denmark & & & & & \\
\hline
\end{tabular}

Science can offer reasonable assessment of effects of..

Mean Ita Can Ger USA Den
$\begin{array}{ll}1 & =\text { strongly disagree } \\ 7 & =\text { strongly agree }\end{array}$

\begin{tabular}{ll}
\hline & Turbulence \\
3.58 & Italy \\
3.08 & Canada \\
3.79 & Germany \\
3.55 & USA \\
4.13 & Denmark \\
& Albedo \\
4.32 & Italy \\
4.46 & Canada \\
4.72 & Germany \\
4.41 & USA \\
4.90 & Denmark \\
& Surface processes \\
3.73 & Italy \\
3.83 & Canada \\
3.71 & Germany \\
3.50 & USA \\
4.06 & Denmark \\
& Sea-ice \\
3.83 & Italy \\
3.86 & Canada \\
4.01 & Germany \\
3.71 & USA \\
3.84 & Denmark \\
& Greenhouse gases \\
4.85 & Italy \\
4.86 & Canada \\
4.71 & Germany \\
4.28 & USA \\
4.61 & Denmark \\
& \\
\hline &
\end{tabular}

clouds, precipitation and atmospheric convection. Using a Student-Newman-Keuls test with a significance level set at 0.05 , the resulting statistical signifi-

${ }^{6}$ Box plots are summary plots based on the median, quartiles, and extreme values. Boxplots are formed from 'boxes', which contain $50 \%$ of the values falling between the 25th and 75th percentiles, and 'whiskers', lines that extend from the box to the highest and lowest values, excluding outliers. A line across the box indicates the median. Boxplots also convey information about spread and skewness. This visualization of the data also allows for a quick assessment in the sample categories. The length of the box indicates the spread of the data within the middle 50th percentile. Outliers are cases with values between 1.5 and 3 box-lengths from the upper or lower edge of the box. Extremes are cases with values more than 3 box-lengths from the upper or lower edge of the box. The whiskers of the box-plot represent the maximum values that do not exceed 1.5-3.0 or $>3$ box lengths. Outliers and extremes are presented as they may represent non-typical responses cant differences indicate some disagreement within the international scientific community. These results are presented in Table 3. As is obvious, these differences are minimal. Figs $1 \& 2$ demonstrate the range of opinion within each scientific community. Fig. 1 addresses the scientific perceptions of the ability of atmospheric climate models to deal with a number of processes. Fig. 2 represents the responses of scientists when asked if the current state of scientific knowledge was developed well enough to allow for a reasonable assessment of the effects of turbulence, surface albedo, land surface processes, sea ice and greenhouse gases. One should note, however, that while there appears to be a reasonable degree of international consensus concerning the ability of science, scientists do not necessarily express an overly high level of confidence in these abilities.

The differences seem to demonstrate that the Italian scientific community often stands in opposition to other 
How well do atmospheric climate models deal with ...

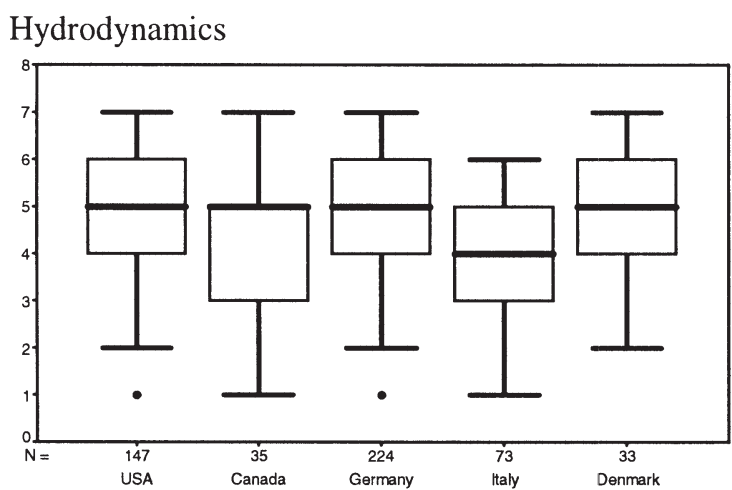

Clouds

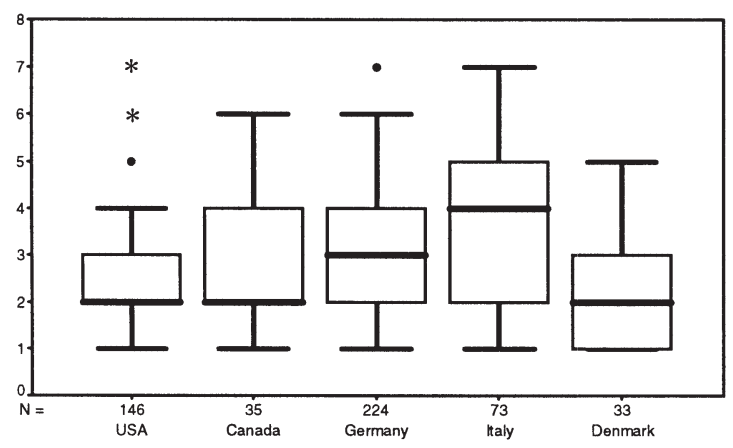

Atmospheric Convection

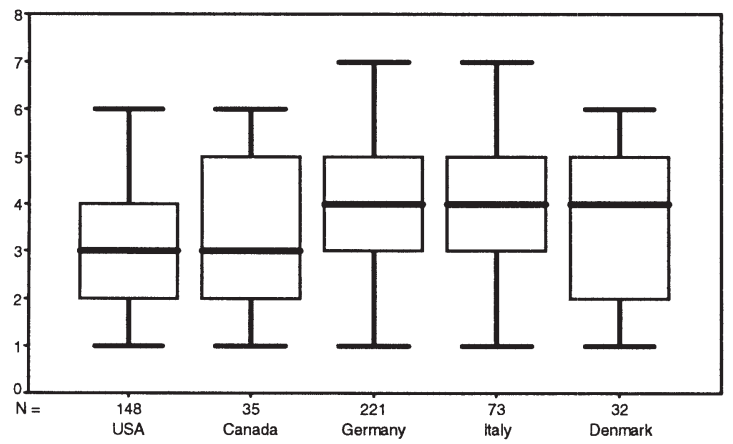

groups in the survey. However, since the overall emphasis in this discussion concerns the German scientific community, one should note that only in the ability to model clouds does the German scientific community differ significantly from other national groupings (with the exception of Italy).

The German scientific community, then, does not differ a great degree from the other groups in this study, at least not in terms of the assessment of the abilities of science. In short, to this point there seems to be a common climate science information base from which all policy interests might draw.
Radiation

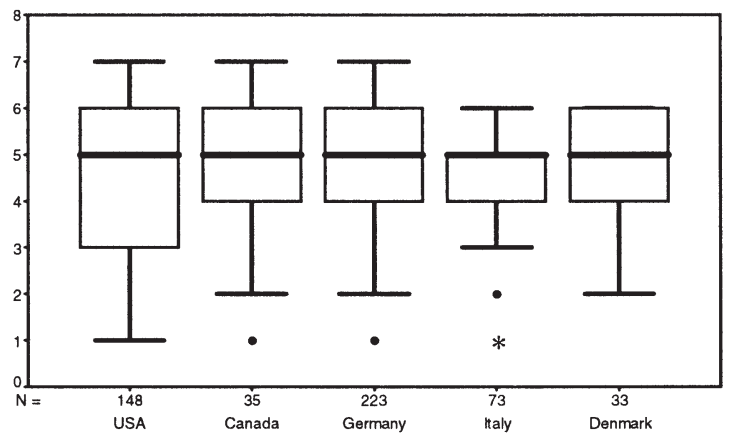

Precipitation

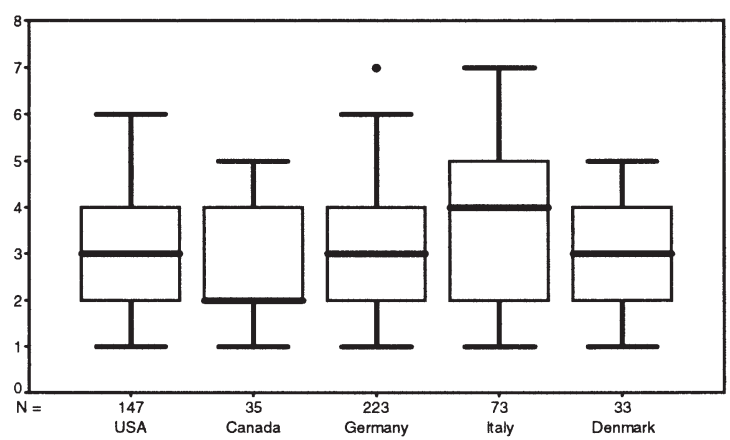

$$
(1=\text { very inadequate, } 7=\text { very adequate })
$$$$
* \text { = extreme value } \cdot=\text { outlier }
$$

Fig. 1. Scientific consensus 1

\section{TOWARDS THE SUBJECTIVE}

Before getting to the German policy interface it is necessary to determine if differences exist in the metamorphosis of the scientific knowledge. Again, the same countries are compared, first to demonstrate the level of consensus in the predictive capabilities of the science, which would be of pragmatic use to policy makers, and subsequently, to assess the nature of the outcome of climate change. The data is represented as above, first in tabular format in Table 4, again indicating statistically significant differences, and then in 
The current state of scientific knowledge is developed well enough to allow for a reasonable assessment of the effects of:

Turbulence

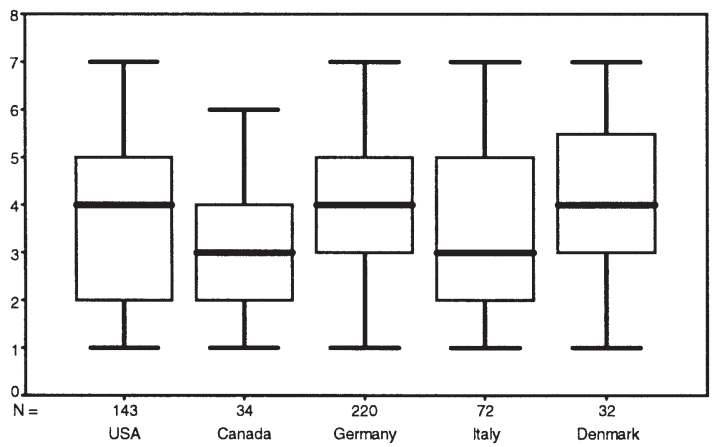

Land Surface Processes

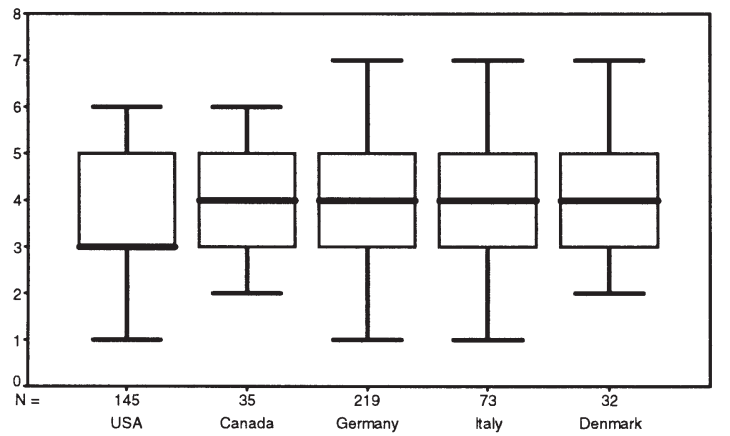

Green House Gases

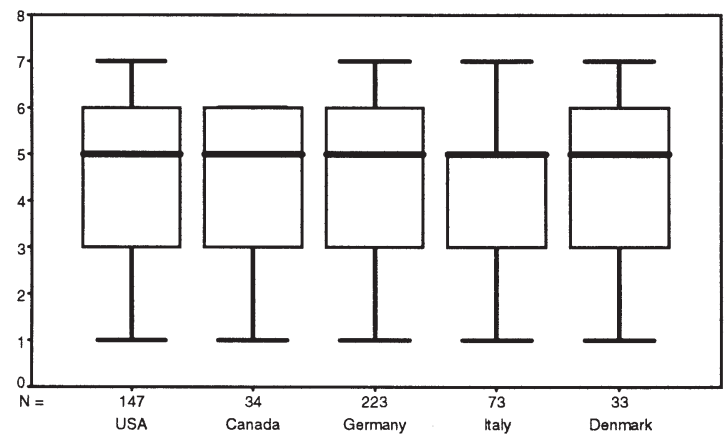

Fig. 3 as a series of box plots to demonstrate individuality within the groupings.

Here it should be noted that in the case of making 10 and $100 \mathrm{yr}$ predictions, Germany stands out as having somewhat more faith in the ability to make such predictions. While the German scientists claim by no means that this ability is perfected, such a marginal distinction might act to sway policy decisions. In Fig. 3 however, note that it is particularly at the $100 \mathrm{yr}$ level of prediction that the perception of German scientists seems to differ.
Surface Albedo

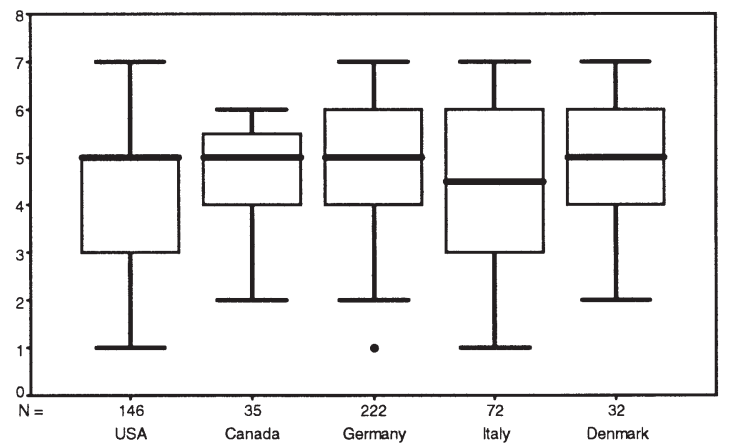

Sea Ice

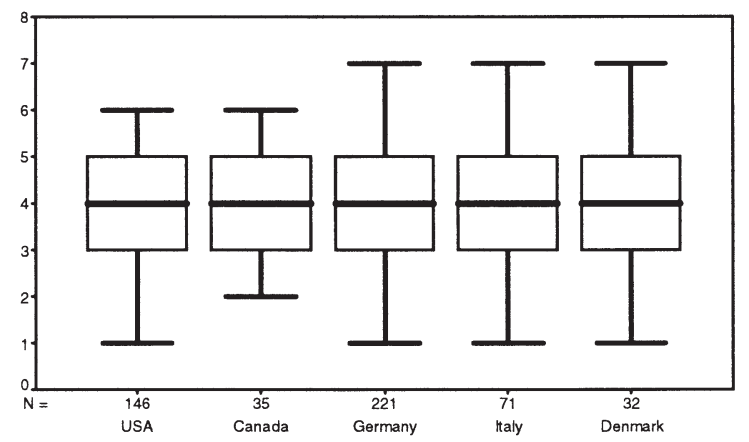

(1 = strongly agree, $7=$ strongly disagree $)$

$*$ extreme value $\bullet^{*}=$ outlier

Fig. 2. Scientific consensus 2

In Fig. 3 evidence further suggests a perspective of an inability to make predictions, marginally increasing with longer climate change time scales. In Fig. 4 it is evident that even the margin of certainty that global warming is underway does not seem to be overwhelmingly convincing. That it will occur in the future is perceived as a stronger possibility; how far in the future, however, remains uncertain (given the results of Fig. 3). Furthermore, there is only a marginal attribution given to anthropogenic causes. Regardless of these assessments, there is the perception of an urgent 
Table 4. Scientists' assessment of the predictive abilities of climate science. ${ }^{*}$ Statistically significant differences

\begin{tabular}{ll}
$\begin{array}{l}\text { Degree science is able to make predictions of... } \\
\text { Mean }\end{array} \quad$ Variable \\
$\begin{array}{ll}1=\text { a great degree } \\
7=\text { none at all }\end{array}$ \\
\hline \multicolumn{3}{l}{ Inter-annual variability } \\
4.85 & Italy \\
4.86 & Canada \\
4.71 & Germany \\
4.28 & USA \\
4.61 & Denmark \\
& Time scale of $\mathbf{1 0} \mathbf{~ y r}$ \\
5.22 & Italy \\
5.03 & Canada \\
4.57 & Germany \\
5.15 & USA \\
4.82 & Denmark \\
& Time scales of $\mathbf{1 0 0} \mathbf{~ y r}$ \\
5.60 & Italy \\
5.20 & Canada \\
4.99 & Germany \\
5.43 & USA \\
5.09 & Denmark \\
& Time scales of $>\mathbf{1 0 0} \mathbf{~ y r}$ \\
5.85 & Italy \\
5.34 & Canada \\
5.30 & Germany \\
5.56 & USA \\
5.42 & Denmark \\
& \\
\hline
\end{tabular}

need for the development and implementation of relevant policy. This must act as a source of confusion to those assigned the task of developing policy, particularly if they do indeed heed the words of science. Note that, albeit by a very small margin, it is the German scientists who perceive the development of policy to be the most urgent. This perhaps is associated with the fact that German scientists also claimed a better understanding of the interaction of climate and society than did scientists in Denmark, Canada and the USA. Indeed, the scientists of both Italy and Germany demonstrate a statistically significant difference from the other samples included in the project when asked their level of agreement with the statement 'Climate scientists are well attuned to the sensitivity of human social systems to climate impacts'. However, further analysis suggests only a very marginal relationship $\left(R^{2}=0.009\right)$ between the claim to understanding the climate-society relationship and the perception of the need for immediate policy consideration, suggesting the possibility that the sense of urgency stems from other sources (Table 5).

Of note, while Germany, the US and Italy disagree on the need for immediate policy decisions, there seems to be a reasonable level of consensus regarding global warming being underway or at least being a prospect for the future if human behaviour does not change. Referring to Fig. 4, it becomes very evident that there is an almost unanimous call for immediate policy decisions in Germany, yet reasons for such a stance remain somewhat unclear. As for the cause of climate change, only Canada lies slightly on the side of attributing it to anthropogenic causes, confusing the matter of policy, especially abatement rather than adaptation policy, even further. One must, at this point, begin to contemplate the role of ideology in scientific opinion, if indeed scientists are calling for policy implementation.

Nonetheless, assuming the need for immediate policy decisions implies that climate change will have environmental and or socio-economic impacts; otherwise one would have to question the need for policy. Since impacts will differ according to region, and policies will need to be implemented regionally, nationally and globally, it is necessary to look at the scientific assessment of the nature of impacts and ability to

Table 5. Global warming and the need for immediate policy decisions. * Statistically significant differences

\begin{tabular}{|c|c|c|c|}
\hline \multicolumn{2}{|c|}{$\begin{array}{l}\text { Mean } \quad \text { Variable } \\
1=\text { strongly disagree } \\
7=\text { strongly agree }\end{array}$} & Ita & Can Ger USA Den \\
\hline & \multicolumn{3}{|c|}{ Global warming is a process already underway } \\
\hline 3.48 & \multicolumn{3}{|l|}{ Italy } \\
\hline 2.89 & \multicolumn{3}{|l|}{ Canada } \\
\hline 3.30 & \multicolumn{3}{|l|}{ Germany } \\
\hline 3.40 & \multicolumn{3}{|l|}{ USA } \\
\hline 3.97 & \multicolumn{3}{|l|}{ Denmark } \\
\hline & \multicolumn{3}{|c|}{$\begin{array}{l}\text { Without change global warming will occur in } \\
\text { the future }\end{array}$} \\
\hline 2.99 & \multicolumn{3}{|c|}{ Italy } \\
\hline 2.06 & \multicolumn{3}{|l|}{ Canada } \\
\hline 2.69 & \multicolumn{3}{|l|}{ Germany } \\
\hline 2.54 & \multicolumn{3}{|l|}{ USA } \\
\hline 2.91 & \multicolumn{3}{|l|}{ Denmark } \\
\hline & \multicolumn{3}{|c|}{$\begin{array}{l}\text { Enough uncertainty that there is } N O \text { need for } \\
\text { immediate policy }\end{array}$} \\
\hline 5.22 & \multicolumn{3}{|c|}{ Italy } \\
\hline 5.69 & \multicolumn{3}{|l|}{ Canada } \\
\hline 5.79 & Germany & * & * \\
\hline 5.32 & \multicolumn{3}{|l|}{ USA } \\
\hline 5.09 & \multicolumn{3}{|l|}{ Denmark } \\
\hline & \multicolumn{3}{|c|}{$\begin{array}{l}\text { Global warming is a result of anthropogenic } \\
\text { causes }\end{array}$} \\
\hline 4.03 & \multicolumn{3}{|c|}{ Italy } \\
\hline 3.31 & \multicolumn{3}{|l|}{ Canada } \\
\hline 4.15 & \multicolumn{3}{|l|}{ Germany } \\
\hline 4.24 & \multicolumn{3}{|l|}{ USA } \\
\hline 5.15 & \multicolumn{3}{|l|}{ Denmark } \\
\hline
\end{tabular}


To what degree is the current state of scientific knowledge able to make reasonable predictions of :

inter-annual variability

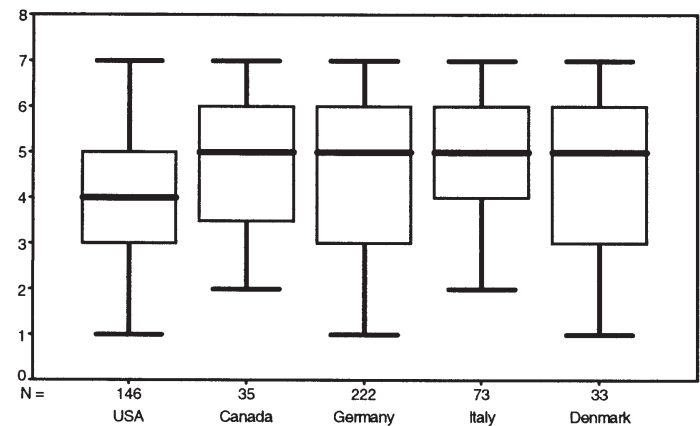

100 years

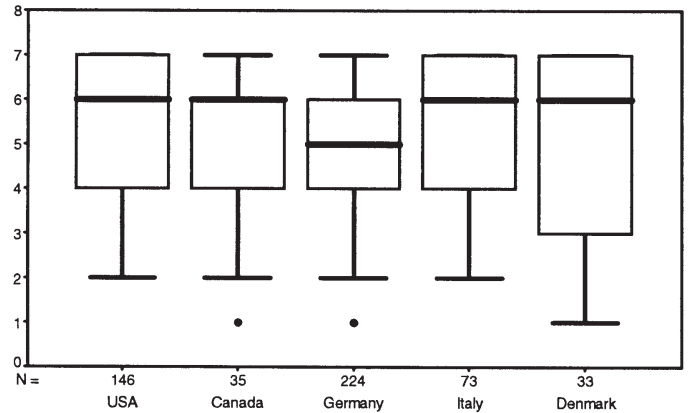

10 years

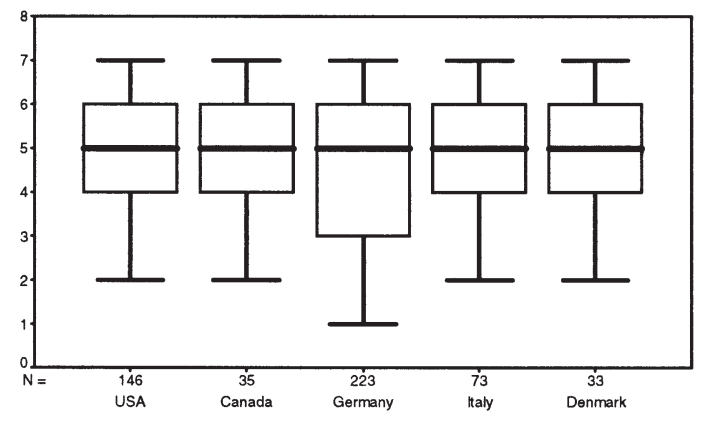

$>100$ years

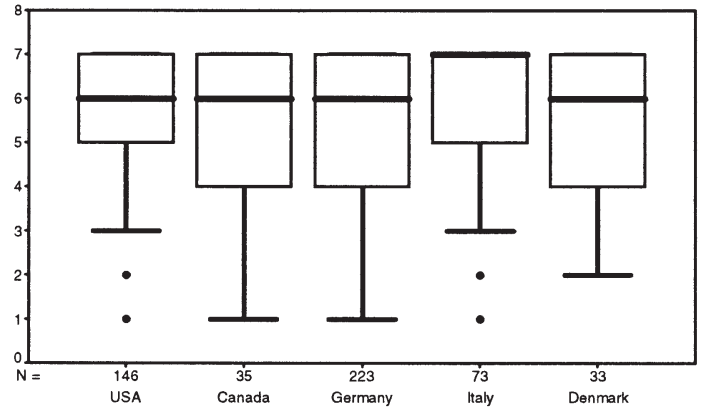

$1=$ a great degree $7=$ none at all $\quad *=$ extreme value $\cdot=$ outlier

Fig. 3. Scientists' assessment of the predictive abilities of climate science

Global warming is a process already underway

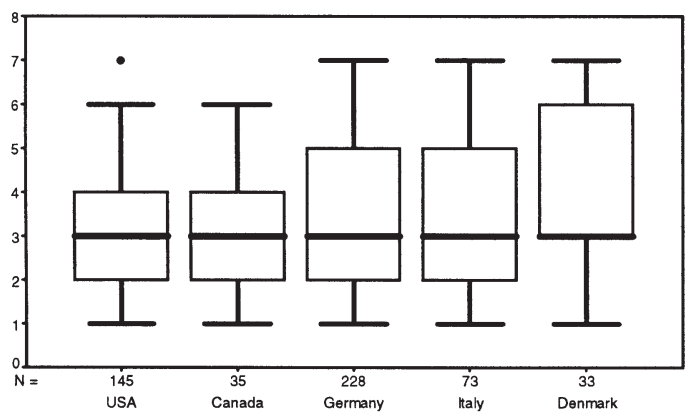

There is enough uncertainty that there is $N O$ need for immediate policy decisions

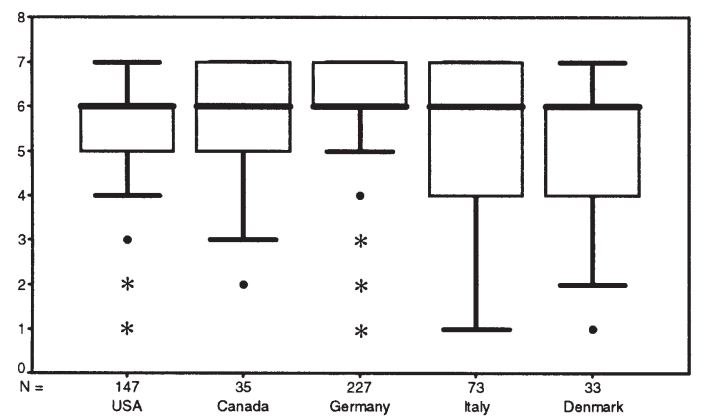

Without change in behaviour global warming will occur in future

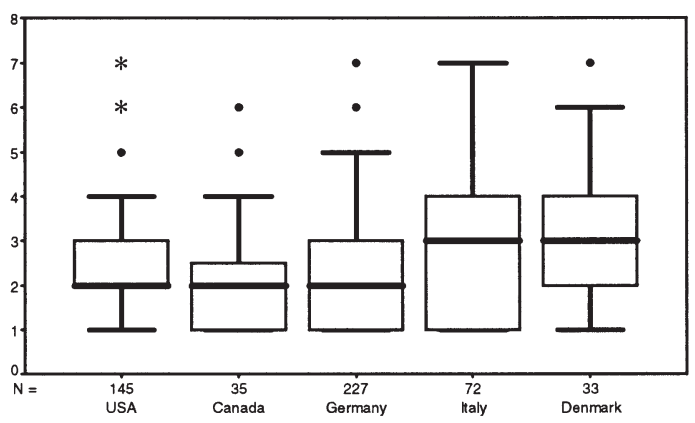

Climate change is mostly the result of anthropogenic causes

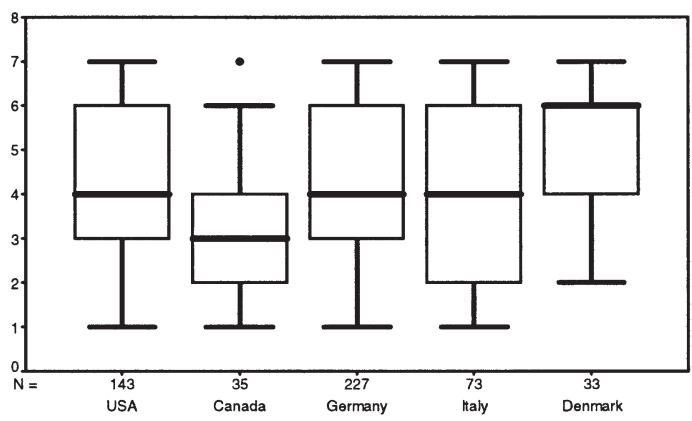

$1=$ strongly agree $7=$ strongly disagree $\quad *$ =xtreme value $\cdot=$ outlier 
Table 6. Perceptions of impacts. *Statistically significant differences

\begin{tabular}{|c|c|c|}
\hline \multicolumn{3}{|c|}{$\begin{array}{l}1=\text { to a great degree } \\
7=\text { not at all }\end{array}$} \\
\hline & \multicolumn{2}{|c|}{$\begin{array}{l}\text { With downscaling it is possible to determine } \\
\text { local climate impacts }\end{array}$} \\
\hline 4.34 & Italy & \\
\hline 5.17 & Canada & \\
\hline 4.72 & Germany & \\
\hline 5.00 & USA & * \\
\hline \multirow[t]{2}{*}{4.71} & Denmark & \\
\hline & \multicolumn{2}{|c|}{$\begin{array}{l}\text { We can explicitly state the detrimental effects of } \\
\text { climate change on society }\end{array}$} \\
\hline 4.35 & \multicolumn{2}{|c|}{ Italy } \\
\hline 4.20 & \multicolumn{2}{|l|}{ Canada } \\
\hline 4.55 & \multicolumn{2}{|l|}{ Germany } \\
\hline 4.58 & \multicolumn{2}{|l|}{ USA } \\
\hline 3.97 & \multicolumn{2}{|l|}{ Denmark } \\
\hline & \multicolumn{2}{|c|}{$\begin{array}{l}\text { Climate change will have detrimental effects } \\
\text { for some societies }\end{array}$} \\
\hline 3.10 & \multirow{2}{*}{\multicolumn{2}{|c|}{$\begin{array}{l}\text { Italy } \\
\text { Canada }\end{array}$}} \\
\hline 2.20 & & \\
\hline 2.29 & \multicolumn{2}{|l|}{ Germany } \\
\hline 2.53 & \multicolumn{2}{|l|}{ USA } \\
\hline 2.30 & \multicolumn{2}{|l|}{ Denmark } \\
\hline & \multicolumn{2}{|c|}{$\begin{array}{l}\text { Climate change will have a detrimental effect } \\
\text { for YOUR society }\end{array}$} \\
\hline 3.63 & \multicolumn{2}{|c|}{ Italy } \\
\hline 4.29 & \multicolumn{2}{|l|}{ Canada } \\
\hline 3.63 & \multicolumn{2}{|l|}{ Germany } \\
\hline 3.80 & \multicolumn{2}{|l|}{ USA } \\
\hline 5.00 & Denmark & * \\
\hline
\end{tabular}

assess regional circumstances. Findings are presented in Table 6 and Fig. 5.

While there appears to be little faith in the ability to determine local climate impacts through the process of downscaling and in the ability to explicitly state the detrimental effects that climate change might have upon society, there is a relatively strong belief that the impacts will nonetheless be negative for some societies. It is not clear how this is determined but if 'some societies' lead a scientist to focus perhaps on the Maldives, then it is safe to assume that climate change and rising sea levels will definitely have a negative impact on 'some societies', and in this case the impact could most likely be stated explicitly. However, the example of the Maldives would constitute more the exception than the rule.

Asked if these negative effects will be experienced by the scientist's host country, the evidence suggests the perceptions that the negative consequences of climate change will be more pronounced elsewhere. Given the fact of the coastal areas and the variety of regional climate types associated with the countries in the study, this interpretation is somewhat contradictory to what would be expected, perhaps suggesting vulnerability is only marginally associated with geophysical processes that are isolated from societal relationships, although it is not necessarily made explicit in much of the work addressing global climate change. In other words, consciously or unconsciously, the advantage of being in the position to respond with a technological fix may shape the perception of the strength of the detriment. It might also suggest that the qualitative factors affecting risk perception and evaluation as outlined by Covello et al. (1989) also influence scientific judgement. These include, among other factors 'catastrophic potential', 'unfamiliarity', 'mechanisms or processes not understood', 'uncontrollability', 'delayed effects', 'risk to future generations', 'lack of trust in responsible institutions', 'much media attention', 'inequitable distributions of risks' and 'caused by human actions or failures'. With the exceptions of 'lack of trust in responsible institutions' and 'much media attention', which will be attended to as the discussion continues, all of these qualitative factors affecting risk perception and evaluation are evident in the scientific perspective of global warming as noted above. While Covello et al. (1989) was not specifically singling out the scientific community when summarizing the factors that are employed in risk assessment, the same factors seem to be well at play within scientific personalities. Gone, it appears at this level, is much of the potential to claim scientific objectivity.

One might be led to the assumption, then, that the perceived predictive powers of the science would lead to the perception of the need for policy. This too proved not to be a statistically significant relationship. It would seem then that it is perhaps climate/weather events, partial evidence and scientific 'intuition' that lead to demands for policy concerns. However, this might also lead to a less than adequate means of addressing the issue, for example, an imbalance between arguments for abatement versus arguments for adaptation might have dire consequences, particularly if natural variability plays a more significant role than anticipated or if proposals for emission abatement measures fail (for a somewhat extended discussion of this issue see Sarewitz \& Pielke 2000). Nonetheless, the climate change issue as it stands is mostly an issue of global abatement rather than regional adaptation. Regardless of possible motives and agendas, the issue of climate change has been addressed predominantly from a global perspective (not, of course, without the suggestion of potentially broad regional impacts) and much of the 'global' dialogue draws its authority and credibility from a single source, namely the IPCC. Consequently it is necessary to discuss how the scientific community assesses the IPCC, the international 
To what degree ...

through the process of downscaling is it now possible to determine local climate impacts

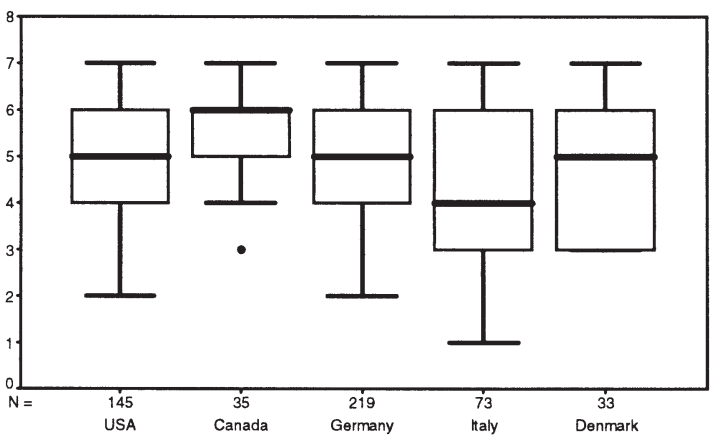

will climate change have detrimental effects for SOME societies

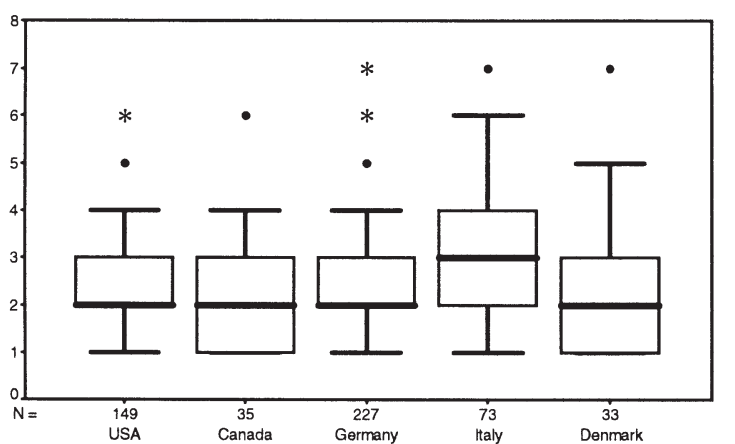

$1=$ a great degree $7=$ none at all can we explicitly state the detrimental effects on society

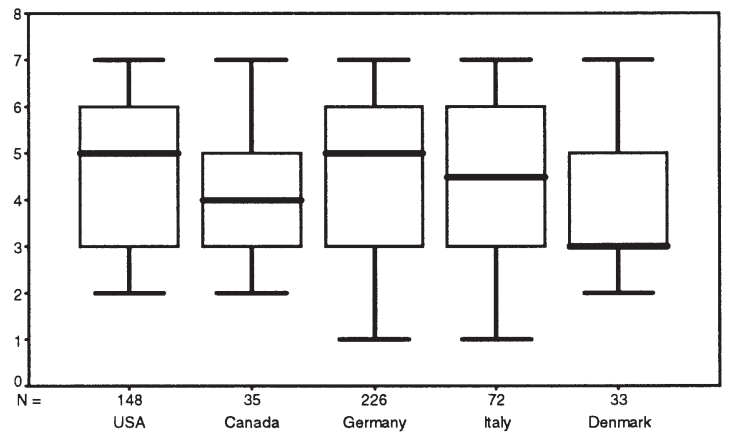

will climate change have detrimental effects for YOUR society

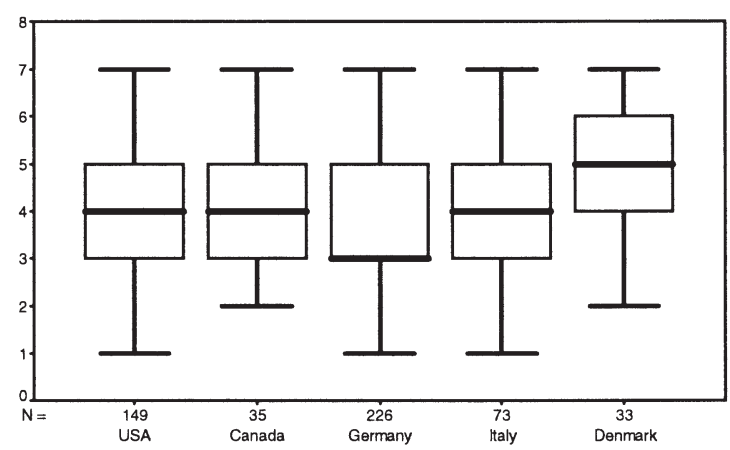

$*$ extreme value $\bullet=$ outlier

Fig. 5. Perceptions of impacts

clearing house of climate information (expert knowledge) and the advisory text for national and international agendas. It has come to represent the state-ofthe-art of the climate sciences and consequently plays a significant role in international communications and international negotiations. As such, the IPCC could be considered as the information silo of the climate sciences.

\section{THE INFORMATION SILO}

The IPCC has become recognized as the pinnacle of international efforts to consolidate the results of climate sciences. However, it seems the results are also open to multiple interpretations as is evident in the failure to ratify most international climate related agreements. Consequently, climate scientists themselves were asked to evaluate the utility of the IPCC. In effect this will assess if the full scope of scientific opinion is reaching the policy debates at the international level, and the impact of such an institute upon the science itself. These results are presented in Fig. 6.

The Canadian science community, it seems, accepts the IPCC reports, more than the other scientific communities, as being of the most utility for the advancement of science and assesses it more than the other samples as reflecting the consensus of scientific thought. Scientist from Denmark were the most convinced that IPCC reports were used in policy making decisions while the medians indicate that scientists from Germany and Italy were the least likely to perceive these reports to be incorporated into the policy process. As to the influence of the IPCC on determining research topics, the medians suggest that each of the scientific communities have at least a minimal level of concern. Statistically significant differences are noted in Table 7. 
The IPCC reports are of great use to the advancement of science

$1=$ strongly agree, 7 = strongly disagree

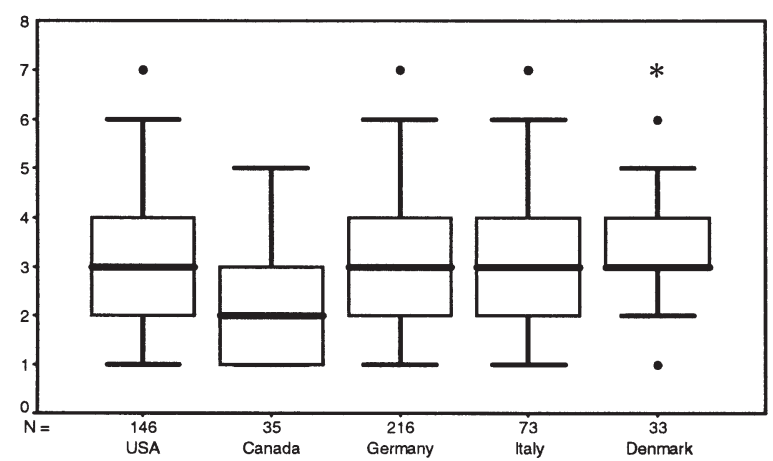

How much do you think IPCC reports are used in the policy making decisions

$1=$ very much, $7=$ not at all

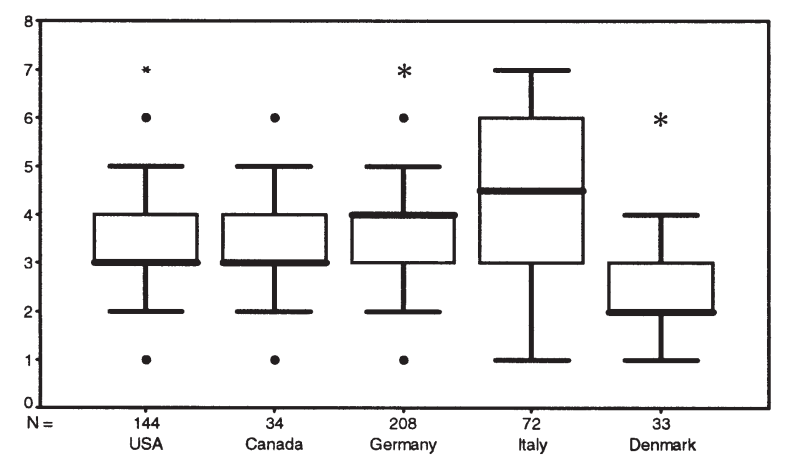

$*$ = extreme value ${ }^{\bullet}=$ outlier
IPCC reports accurately reflect scientific consensus

$1=$ strongly agree, 7 = strongly disagree

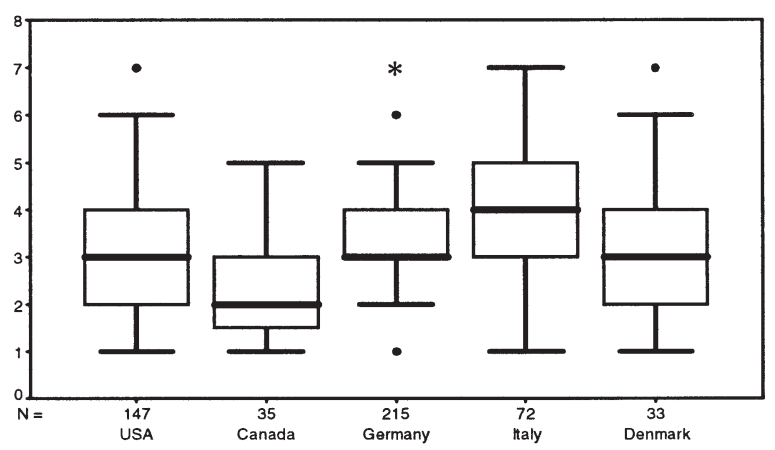

How much influence do you think the IPCC has over what areas come to be considered worthy research topics

$1=$ a great influence, $7=$ no influence

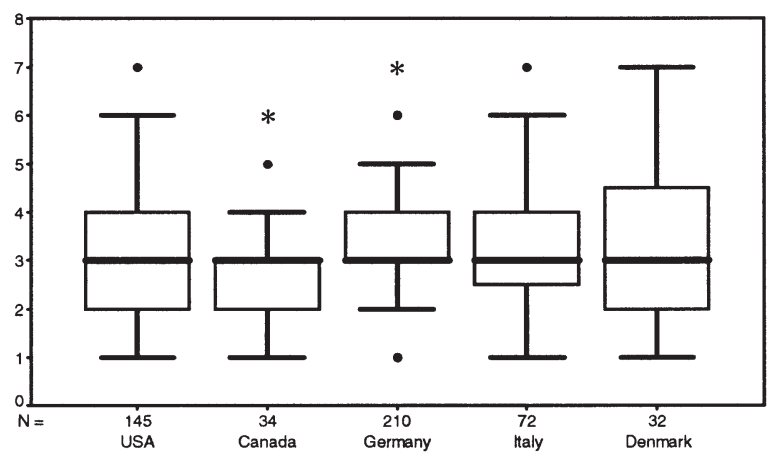

Fig. 6. Climate scientists' assessment of the IPCC

As for the perceptions of German policy makers, they rated the IPCC reports as being among the lesser important sources of information. This is evident in Fig. 7. In fact, at the regional level, Länder, the IPCC reports are somewhat of an unknown entity.

This would indicate that different levels of government perhaps rely on different sources of information, giving rise to the potential for conflict regarding even national policy implementation. On the other hand, given the participatory opportunities of regional government in international affairs, 'global' issues might be of little concern to regional levels of government. Unfortunately, as noted by climate scientists, it remains difficult to address explicit regional climate impacts, thereby removing the issue from the very realm in which the impacts and policy implementations will be experienced.

\section{THE INFLUENCE OF POLITICS ON SCIENCE}

Since we are dealing with the relationship between science and policy, one final international comparison is necessary, that is, the scientists' perceptions of the influence of policy on science. These results are depicted in Fig. 8. Consistent with previous presentations, statistically significant differences are noted in Table 8 .

Here it is apparent that among the samples there is a common sentiment that to some degree research is being influenced by politics and that policy makers are, to some degree, able to persuade scientists to redefine the perception of the issue. It is interesting to note, however, that there appears to be a contrast between scientists in North America and European scientists when it comes to questioning the political pres- 
Table 7. Scientists' perceptions of the IPCC. *Statistically significant differences

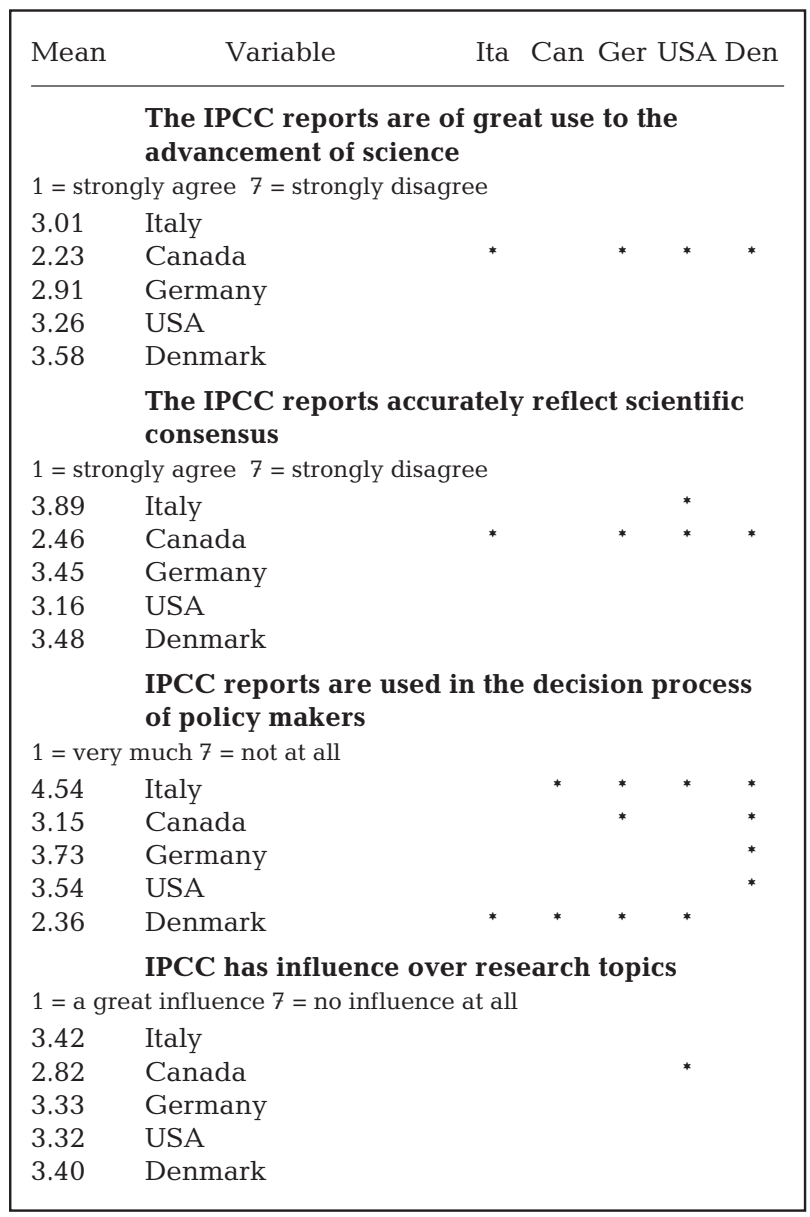

sure for science to be justified in terms of policy relevance. According to the data one could conclude that there is less pressure, or the perception of less pressure, within the European scientific community as represented by the sample groups. This might or might not be justified, but definitive proof is beyond the scope of this paper.

\section{INTRODUCTION TO SCIENCE-POLICY COMMUNICATION IN GERMANY}

Since we are dealing with communication between scientists and policy makers, it is necessary to also include a comparison of patterns of communication. These are represented in Fig. 9. There is one (repeated) notable exception here, and that is the extent of the climate scientists' claim to understanding things sociological as they pertain to climate change. Note here that Germany and Italy stand out from the other groups. One would expect that such a claim might lead to an increased pattern of interaction between policy makers and climate scientists. However, the contrary seems to be the rule, with German scientists claiming to have a minimal amount of contact with policy makers and the media.

After having located the German science community in the international context, it is necessary to begin to address only the German sample of scientists so as to delineate some of its characteristics. Before discussing the relationship between climate science and policy in Germany, it is also necessary to back track and to provide a brief introduction to the rise of climate sciences in Germany so as to provide a framework in which to couch the following analysis, indicating that from its inception, there has been a strong link between the science of climate change and politics. Borscher et al. (1997, p. 10) succinctly outlined the 'Phases of the climate change issue in Germany' as follows:

Phase 1. 1970-1975: Prehistory. In the early 1970s, initiatives by international organizations like the WMO [World Meteorological Organization] alerted the German scientific community to the possibility of man-made alterations of the atmosphere. Government-independent research associations like the DFG [German Research Foundation] and the Max Planck Society reacted by creating [research and development] support schemes intended to bring German science up to date with international developments. Nevertheless, climate research remained a minor area of

Table 8. The influence of policy on science. * Statistically significant differences

\begin{tabular}{|c|c|c|c|c|}
\hline Mean & Variable & Ita & Can $\mathrm{C}$ & Ger USA Den \\
\hline \multicolumn{5}{|c|}{ Research is influenced by politics } \\
\hline 3.23 & \multicolumn{4}{|l|}{ Italy } \\
\hline 3.00 & \multicolumn{4}{|l|}{ Canada } \\
\hline 3.27 & \multicolumn{4}{|l|}{ Germany } \\
\hline 2.99 & \multicolumn{4}{|l|}{ USA } \\
\hline 2.97 & \multicolumn{4}{|l|}{ Denmark } \\
\hline & \multicolumn{4}{|c|}{$\begin{array}{l}\text { Policy makers are influential in causing scientists } \\
\text { to redefine his or her perception of the issue }\end{array}$} \\
\hline \multicolumn{5}{|c|}{$1=$ a great degree $7=$ not at all } \\
\hline 3.74 & \multicolumn{4}{|c|}{ Italy } \\
\hline 2.54 & \multicolumn{4}{|l|}{ Canada } \\
\hline 3.21 & \multicolumn{4}{|l|}{ Germany } \\
\hline 2.34 & \multicolumn{4}{|l|}{ USA } \\
\hline 3.33 & \multicolumn{4}{|l|}{ Denmark } \\
\hline & \multicolumn{4}{|c|}{$\begin{array}{l}\text { Pressure for climate research to be justified in } \\
\text { terms of policy relevance }\end{array}$} \\
\hline \multicolumn{5}{|c|}{$1=$ a great degree $7=$ none at all } \\
\hline 3.73 & Italy & & & * \\
\hline 2.54 & Canada & * & & * \\
\hline 3.21 & Germany & * & & \\
\hline 2.34 & USA & $*$ & & * \\
\hline 3.33 & Denmark & & & \\
\hline
\end{tabular}


I am familiar with the IPCC reports $1=$ very $7=$ not at all

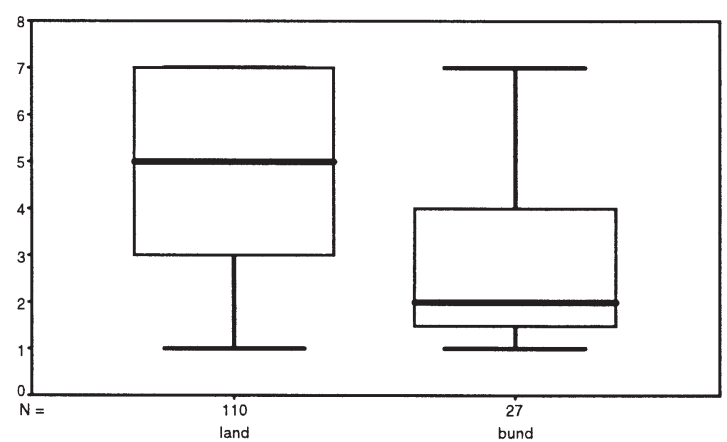

The IPCC reports are of great use to my work

$1=$ very useful $7=$ not useful at all

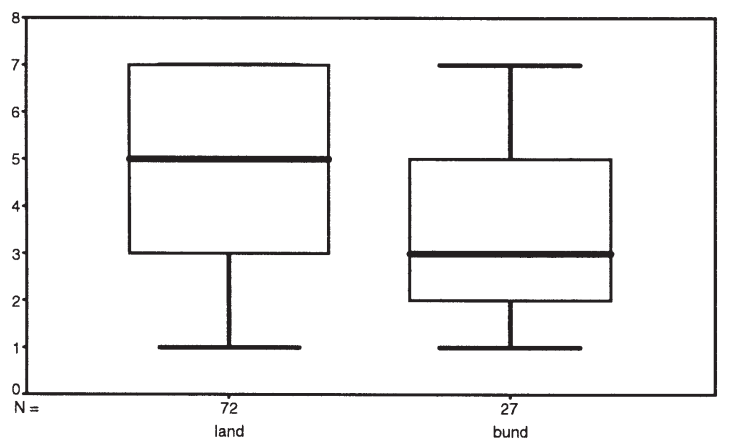

To what degree do you think the pressure for consensus in the IPCC disguises scientific controversy $1=$ great degree $7=$ not at all

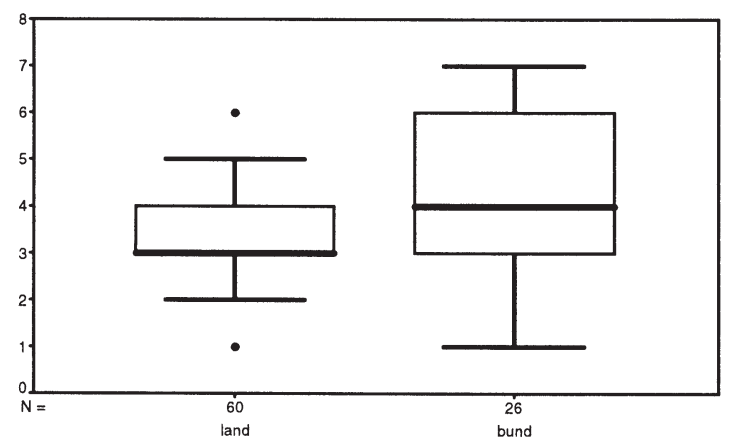

$*$ = extreme value $\cdot=$ outlier
IPCC reports are of great use for policy making $1=$ very useful $7=$ not useful at all

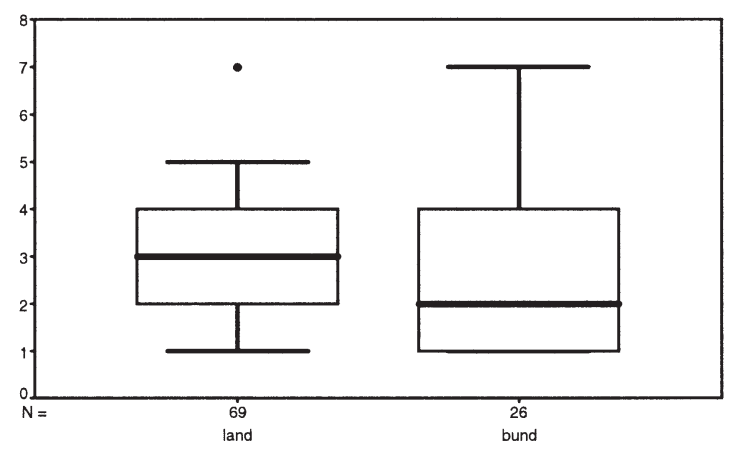

The IPCC Reports accurately represent the opinion of the scientific community $1=$ very much $7=$ not at all

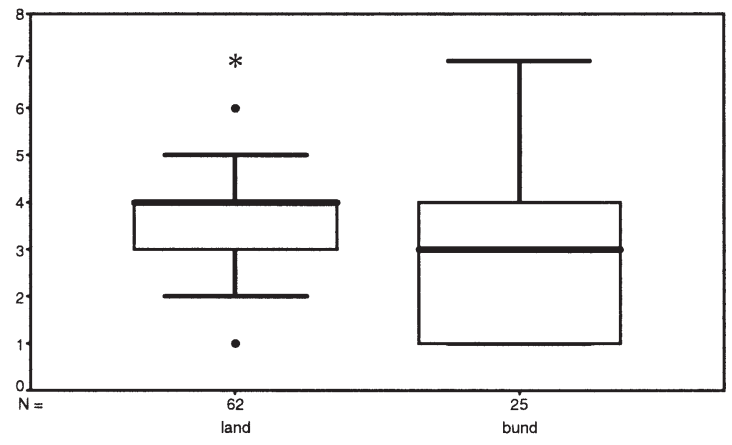

The fact of differing opinions is marginalized by the IPCC $1=$ very much $7=$ not at all

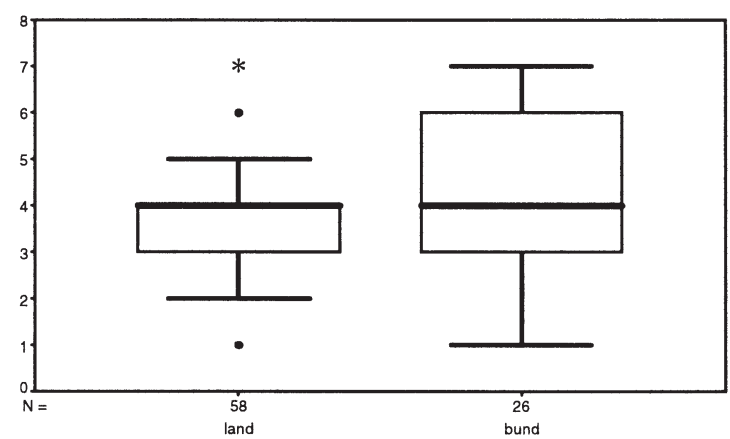

Fig. 7. German Exekutive assessment of the IPCC

the science system. And although environmental policy in general became an established part of German politics in the 1970s, climate research created only a very limited response in politics.
Phase 2. 1978-1984: Monitoring and preparation. In the late $1970 \mathrm{~s}$, again in reaction to international developments, German politics started organising some international conferences [Borschers et al. do not 
How much do you think the direction of research has been influenced by external politics

$1=$ very much $7=$ not at all

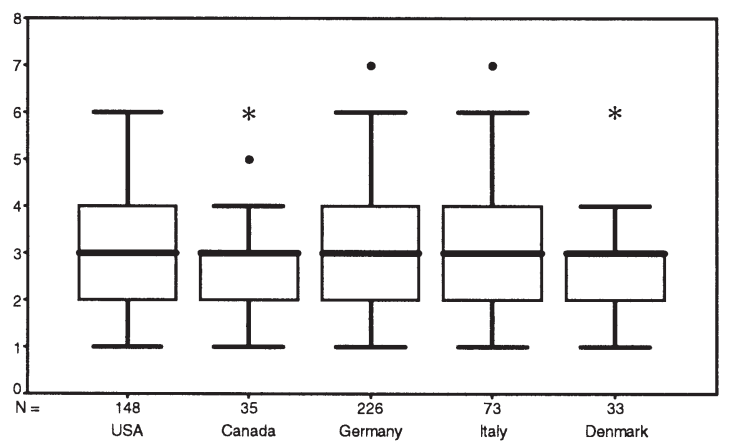

To what degree do you think there is pressure for climate research to be justified in terms of policy relevance?

$1=$ a great degree $7=$ none at all

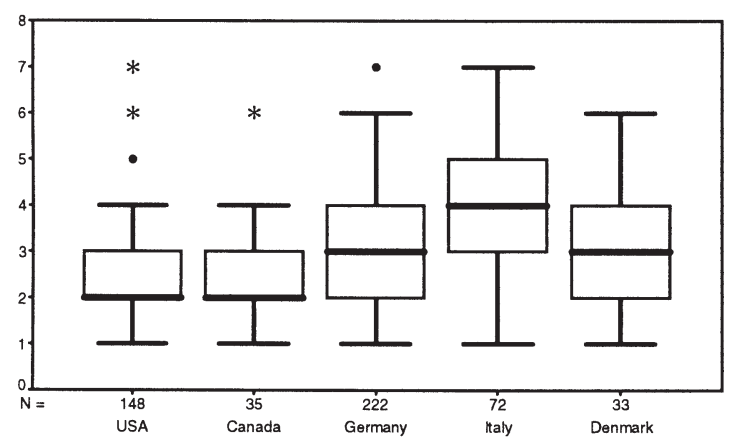

explicitly state the tittles, locations, themes, or dates of these conferences] and increasing research budgets to form a Federal Climate Research program in 1984. Two factors caused this shift of gear: a few scientists had adopted the issue and started campaigning for it in the media and political circles; and The First World Climate Conference of 1979 signaled to the government that the issue would sooner or later appear on the international policy agenda and required the development of a political strategy. Yet climate remained one of the minor issues on the environmental and research policy agenda.

Phase 3. 1985-1990: Corporatist consensus formation. Between 1985 and 1990, a consensus among scientists and politicians on the existence of the global warming threat was established by the first parliamentarian Study Commission on the Protection of the Earth's Atmosphere. International developments and various issue linkages combined with this to make climate change a priority in science and policy. The federal government decided it wanted to be prepared and
To what degree do you think policy makers are influential in causing scientists to redefine their perceptions of an issue? $1=$ a great degree $7=$ not at all

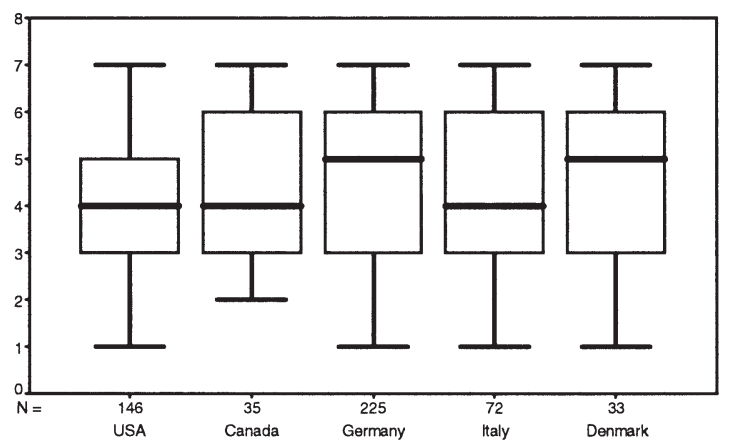

$$
* \text { = extreme values } \bullet=\text { outlier }
$$

Fig. 8. Scientists' views regarding the politicization of science

become an international pace maker, deciding in 1990 that Germany would reduce its $\mathrm{CO}_{2}$ emissions by $25 \%$ in 2005. Federal funding of climate research grew steeply between 1985 and 1990 and climate research expanded into a new and recognized research field in the German research system.

Phase 4. 1991-1997: Transition to incrementalist stabilization. After 1991, the climate issue reached a phase of institutionalization and incrementalist stabilization. On the one hand, climate change had now reached the national policy level and had become and accepted and independent domain, with a strong institutional basis in German science and politics alike. On the other hand, the issue now also had to fully compete with other policy issues like economic policy, energy policy, traffic policy, taxation and wider issues of economic competitiveness.

Climate science, by this time, held major implications for the construction of policy. However, science in Germany at this time also prided itself in basic rather than policy driven research. 
Climate scientists are well attuned to the sensitivity of human social systems $1=$ strongly agree $7=$ strongly disagree

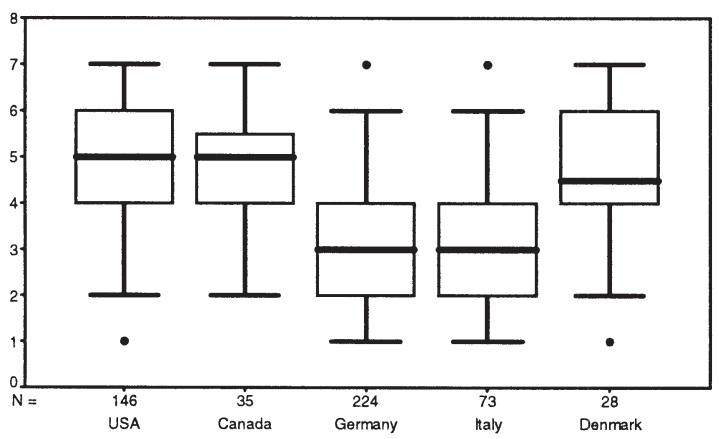

How much have you been involved with those people who make climate policy?

$1=$ very much $7=$ not at all

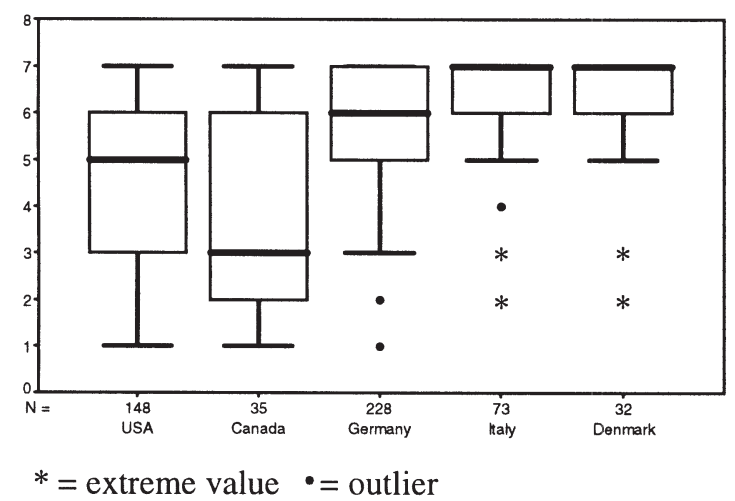

How often are you contacted by the media for information pertaining to climate change

$1=$ very often $7=$ not at all

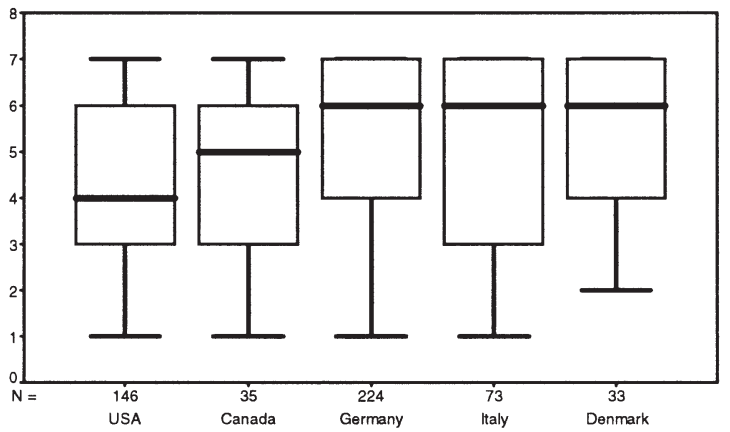

How much do you think a scientist's exposure to publicity influences the direction of his or her research?

$1=$ very much $7=$ not at all

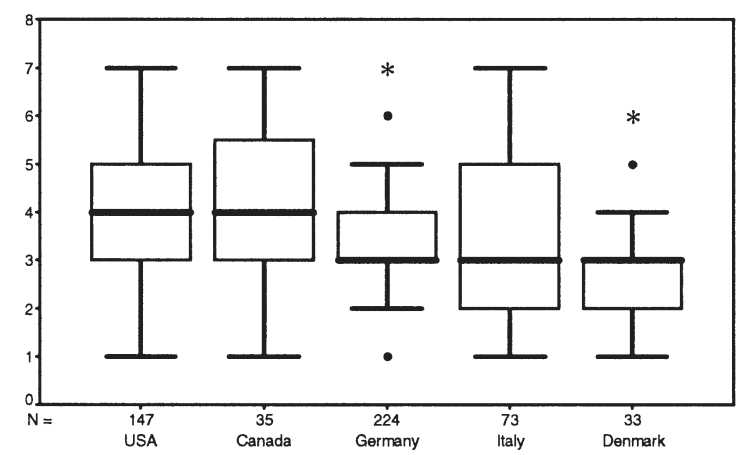

Fig. 9. Comparative levels of external contact and extended expertise

Since we are dealing with the process of science communication, it is necessary to address not only the content but also the means of communication. While other means exist, the discussion in this paper is limited to direct communications with the media and direct communications with policy decision makers. The media are included since they are a significant indirect source of information for policy decision makers. (This becomes evident when asking decision makers to rank their sources of relevant information.) Table 9 indicates patterns of communication, demonstrating that while external contact is limited, some scientists tend to communicate more with media outlets while others are more inclined to have contact with policy decision makers.

For the purpose of this analysis, the lower right hand quadrant, that is those with values $>3$, is designated as the group with low levels of external contact with the body politic or the media. Few of the scientists from the German sample claim to have a high level of contact with either the media or policy makers. Consequently it becomes meaningful to make such a distinction in the subsequent analyses. It is also necessary at this point to introduce the political consumer of the scientific information, namely the sample from the German Exekutive.

\section{COMPARATIVE GERMAN PERSPECTIVE OF CLIMATE CHANGE: SCIENTISTS AND POLICY MAKERS}

The political experts were asked about their level of certainty when dealing with the issue of climate change. (In all of the following figures which include the German climate science community and the Exeku- 
Table 9. German scientists' contact with the media and policy makers. The grand total of 224 does not correspond with the total sample size since 4 respondents did not answer the question regarding media contact. Those 4 respondents fell into the category of low contact with policy makers. Italics: low levels of external contact

\begin{tabular}{|c|c|c|c|c|c|c|c|c|}
\hline \multirow{2}{*}{$\begin{array}{l}\text { How much have you been } \\
\text { involved with the media? }\end{array}$} & \multicolumn{8}{|c|}{ How much have you been involved with policy makers? } \\
\hline & Very much & 2 & 3 & 4 & 5 & 6 & Not at all & Total \\
\hline Very much & & 1 & & & & 2 & & 3 \\
\hline 2 & & 2 & 1 & 1 & 3 & 4 & 5 & 16 \\
\hline 3 & 1 & & 3 & 3 & 3 & 8 & 5 & 23 \\
\hline 4 & & 1 & 4 & 5 & 4 & 7 & 2 & 23 \\
\hline 5 & & & 4 & 3 & 3 & 14 & 8 & 32 \\
\hline 6 & & & 5 & & 8 & 20 & 16 & 49 \\
\hline Not at all & 2 & 1 & 3 & 3 & 1 & 6 & 62 & 78 \\
\hline Total & 3 & 5 & 20 & 15 & 22 & 61 & 98 & 224 \\
\hline
\end{tabular}

tive the distinction is made between government levels: the Länder being the more regional [state, provincial] level, and the federal level of government identified as the Bund. Further refinement is made for scientists according to high and low levels of contact between science and the media, and between science and policy.) Concerning the seriousness of climate change, both scientists and members of the Exekutive were asked the same question: 'How much do you think global climate change is one of the leading problems facing humanity?', with a value of 1 indicating 'very much' and a value of 7 indicating 'not at all' as a response. The results for this question are presented in Table 10.

It becomes apparent that the greatest sense of urgency assigned to global climate change is from members of the government, not from the scientific community. Perhaps the increased urgency assigned to the problem of climate change is not the result of employing the state of the art of scientific knowledge, but more to do with the sources of knowledge that government members draw from, or perhaps as a result of concurrent political, social and economic trends, i.e.

Table 10. The perception of climate change as a global social problem: How much do you think global climate change is one of the leading problems facing humanity? $1=$ very much, $7=$ not at all

\begin{tabular}{|lrrr|}
\hline Sample group & Mean & SD & $\mathrm{n}$ \\
\hline German scientists & & & \\
With high media contact & 3.40 & 1.63 & 42 \\
With low media contact & 3.25 & 1.63 & 181 \\
German scientists & & & \\
With high policy maker contact & 3.25 & 1.76 & 28 \\
With low policy maker contact & 3.24 & 1.64 & 199 \\
Deutsche Exekutive & & & \\
Bund & 2.80 & 1.30 & 120 \\
Länder & 2.50 & 1.50 & 27 \\
\hline
\end{tabular}

'green' politics. (At the other end of the spectrum, elsewhere, perhaps we have 'economy at all costs' politics having equal input. However this is beyond the scope of the available data and, subsequently, beyond the scope of this paper.)

Sources of information for policy makers are by no means limited to those of the traditional scientific community. Other sources of information might include, for instance, internal working groups, and/or popular media formats such as television or newspapers. In short, there might be competing sources of knowledge in which peer reviewed scientific documents are sometimes relegated to be less than an optimal source of information, or other sources might simply better meet the political needs of the time. Consequently it might be that the Exekutive at times relies on the interpretation of information (expert knowledge into pragmatic knowledge) to be conducted by other, external means. To assess this possibility, members of the Exekutive were asked to rate sources of information they considered as being important. These results are presented in Fig. 10.

Of particular importance here, given that this paper addresses communication of science, is the fact that at the Länder level, daily and weekly newspapers are ranked almost the equivalent to scientific journals as sources of information, and it is precisely at these regional levels that policy, especially adaptation policy, is likely to be put into practice. Given the tendency of the media at times to turn towards sensationalism, it is no wonder, as indicated in Table 10, that these regional levels are more likely to perceive climate change policy as most urgent. While the IPCC reports appear to be of importance at the national level of policy, obviously for reasons of international negotiation, they are only marginally significant at the regional level. In fact, $23 \%$ of the sample of Länder-level respondents did not answer the question regarding the importance of the IPCC reports, suggesting perhaps 
What are your most important sources of information about climate issues and the atmosphere?

Land

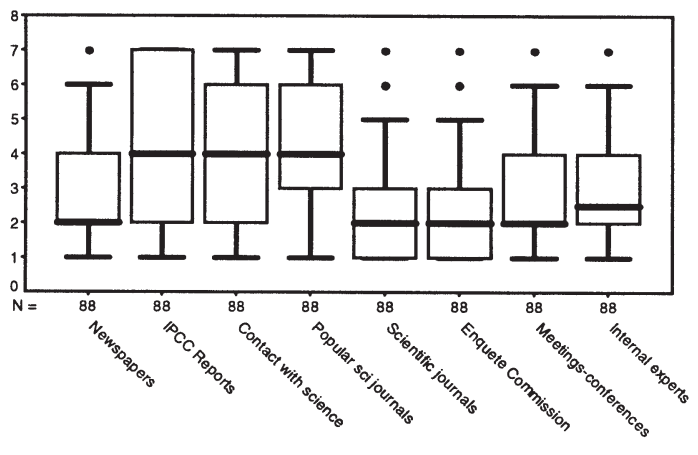

$1=$ Important $7=$ Unimportant
Bund

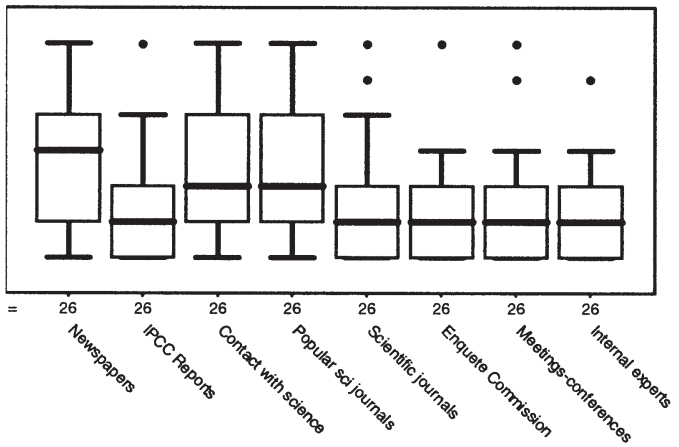

Fig. 10. Sources of information for the Exekutive

Table 11. Is global warming underway and can it be attributed to anthropogenic causes? $1=$ strongly agree, $7=$ strongly disagree

\begin{tabular}{|c|c|c|c|c|c|c|}
\hline \multirow[t]{2}{*}{ Sample group } & \multicolumn{3}{|c|}{ Global warming is underway } & \multicolumn{3}{|c|}{ Anthropogenic causes } \\
\hline & Mean & $\mathrm{SD}$ & $\mathrm{n}$ & Mean & $\mathrm{SD}$ & $\mathrm{n}$ \\
\hline \multicolumn{7}{|l|}{ German scientists } \\
\hline With high media contact & 3.50 & 1.77 & 42 & 4.15 & 1.93 & 41 \\
\hline With low media contact & 3.26 & 1.74 & 182 & 4.15 & 1.90 & 182 \\
\hline \multicolumn{7}{|l|}{ German scientists } \\
\hline With high policy maker contact & 3.36 & 1.91 & 28 & 3.89 & 2.17 & 28 \\
\hline With low policy maker contact & 3.29 & 1.73 & 200 & 4.19 & 1.87 & 199 \\
\hline International sample of scientists & 3.39 & 1.68 & 542 & 4.17 & 1.80 & 539 \\
\hline \multicolumn{7}{|l|}{ Exekutive } \\
\hline Bund & 2.63 & 1.55 & 27 & 3.48 & 1.92 & 27 \\
\hline Länder & 3.00 & 1.60 & 120 & 2.89 & 1.58 & 120 \\
\hline
\end{tabular}

they were unaware of what they are or of their existence, and those that did rated them as the least valued source of information. At the federal level, it appears the most highly appraised source of information is drawn from internal experts and working groups, again suggesting the potential for knowledge to be shaped towards desired political ends.

With this in mind, it is necessary to assess how the policy realm views the issue of climate change when compared to the scientific perspective. Results are presented in Table 11. Both scientists and policy makers were asked if indeed global warming is underway and if it was the result of anthropogenic causes. The results indicate that policy makers are more inclined than the scientific community to accept that climate change is underway and much more ready to attribute the causes to anthropogenic influences, a cause very compatible with the political needs, that is, a cause and solution in a social and political context. It is also a possibility that the message reaching policy and public, by whatever means, might indeed be exaggerated. However, on the one hand, this attribution might emphasize the role of politics (rather than science) in determining political answers to scientific questions. On the other hand, we cannot expect quantified scientific results to provide complete answers for what are essentially political questions, as in the case of the climate change issue.

Table 12. The use of state-of-the-art knowledge. How often do you think policy makers draw on the most current and state-of-the-art knowledge of the climate sciences? $1=$ always, $7=$ never

\begin{tabular}{|lccr|}
\hline Sample group & Mean & SD & $\mathrm{n}$ \\
\hline High policy contact & 4.30 & 0.99 & 27 \\
Low policy contact & 4.42 & 1.23 & 196 \\
High media contact & 4.32 & 1.25 & 40 \\
Low media contact & 4.41 & 1.20 & 179 \\
\hline
\end{tabular}


Table 11 suggests that the decision makers are marginally more convinced than the scientists that global warming is underway and that it is the result of anthropogenic causes. This, perhaps as well as being attributed to the choices of information sources, could reflect the inadequacy of the scientists in conveying the uncertainties of the scientific evidence, or the inability of policy makers to understand this uncertainty. Whereas the scientists consider these uncertainties in making their responses, decision makers might neither understand these uncertainties or might, at the extreme, be unaware of them. As a result they might tend to err on the side of caution. As presented in Table 12, when scientists (all scientists) were asked about the relationship between science and politics, in particular regarding the perception of the policy makers' use of state-of-the-art information, they seem to indicate that, at least in some cases, the state-of-the-art might not be reaching the policy decision making realm.

This suggests a less than optimal dialogue between science and decision makers, with fault assigned to neither. An assessment of the relationship from the perspective of the decision makers is presented in Fig. 11. Here is should be noted that the federal level tends to perceive the relationship between science and policy to be somewhat better than the perceptions of the regional-level decision makers. This, of course, is to be expected, since the federal level of decision makers would be more specialized and united somewhat by federal concerns, whereas regional administration is differentiated according to the needs of the region. Nonetheless, on all accounts, the relationship between science and politics is perceived of as having much room for improvement. Perhaps increased contact and a more open dialogue would act to introduce the science community to the reality and needs of the political realm and vice versa. This, of course, is more easily suggested than implemented.

The less than acceptable claim that the results of science are presented in an understandable manner again points to confusion at the decision making level, perhaps adding to the tendency to consult other than scientific advice concerning the issue. This, of course, includes providing understandable details of the uncertainties of the science, as are well noted by the scientists. It would seem it is not a matter of hiding these uncertainties, rather it is a matter of the inability to convey them in a clear manner. Again, this reflects the inability of traditional scientific procedures to translate information (expert-knowledge) into pragmatic political knowledge. It seems too that scientists in general are less likely to conceive of the needs of the decision maker as being overly important, as is likely typical and accepted as practice in basic research. (However, it also might be desirable to maintain a separation between science and politics if one looks at some of the events of recent history.) Nonetheless, the nature of the problem of global climate change is far from typical, perhaps demanding a reassessment of the relationship between science and policy, at least in the context of such postnormal problems. Perhaps one way to overcome these barriers and still retain somewhat of a distance between science and policy would be the inclusion of increased representation of policy personnel and scientific personnel on relevant funding review committees.

Scientists too were given the opportunity to assess the relationship between science and policy. These results are presented in Fig. 12. It appears they are even less satisfied with the relationship than are the people working in the policy area and readily admit that they are ill-informed as to the needs of policy makers In fact, scientists claim their efforts do little to shape the policy related to global warming, and it is more likely that politics is shaping science rather than vice versa. This is particularly evident among those scientists claiming a higher level of contact with the policy decision makers. However, while the scientific community may be prone to the forces of political persuasion, it seems the scientists at the level of the individual do not express a similar susceptibility, although there seems to be an acute awareness of pressure for science to be increasingly policy-relevant.

\section{CONCLUSION}

The process of communication of complex scientific information to policy makers, that is, the transition from scientific information to socio-political knowledge is a difficult task. To undergo the transition from scientific problem to knowledge for policy decisions requires intricate patterns of integration and cooperation and the more complex the necessary knowledge, the greater the difficulty of integration. For example, as we move from the geophysical climate science towards political and social implications, we move towards territory that is not so easily 'modelled' and a territory that is open to the infinite choices and the influences of human agency. As things stand, 'The mounting reliance of everybody in modern society on the judgments of 'experts' is paralleled by the growing ability of many of us, reinforced by modern media, to deconstruct political reassurance couched as scientific or technical 'fact'. This has been the classic pattern in environmental controversies over the past 2 decades ...' (Grove-White 1998, p. 50). To this we might add that perhaps there is a mounting reliance of politicians on the judgments of non-experts, to deconstruct scientific evidence to suit political needs. This is not a new observation by any means. However, perhaps 
The general working relationship between politics and science:

$1=$ very good $7=$ very poor

Your contact with climate sciences: $1=$ very good $7=$ very poor

Scientists are knowledgeable about the political process: $1=$ true $7=$ false

Scientists know what information I need to do my job: $1=$ true $7=$ false

The results of science are presented in an understandable manner: $1=$ true $7=$ false

Sufficient attention is given to explaining uncertainties: $1=$ true $7=$ false

There are communication difficulties between science and politics: $1=$ true $7=$ false

How often are you approached by scientists regarding your information needs: $1=$ often $7=$ never

How often do you contact scientists for advice or information: $1=$ often $7=$ never

The results of commissioned studies are mostly very useful: $1=$ true $7=$ false

Commissioned studies tend to produce predictable results $1=$ true $7=$ false

Political experts are sometimes presented with only some of the facts: $1=$ true

7 = false

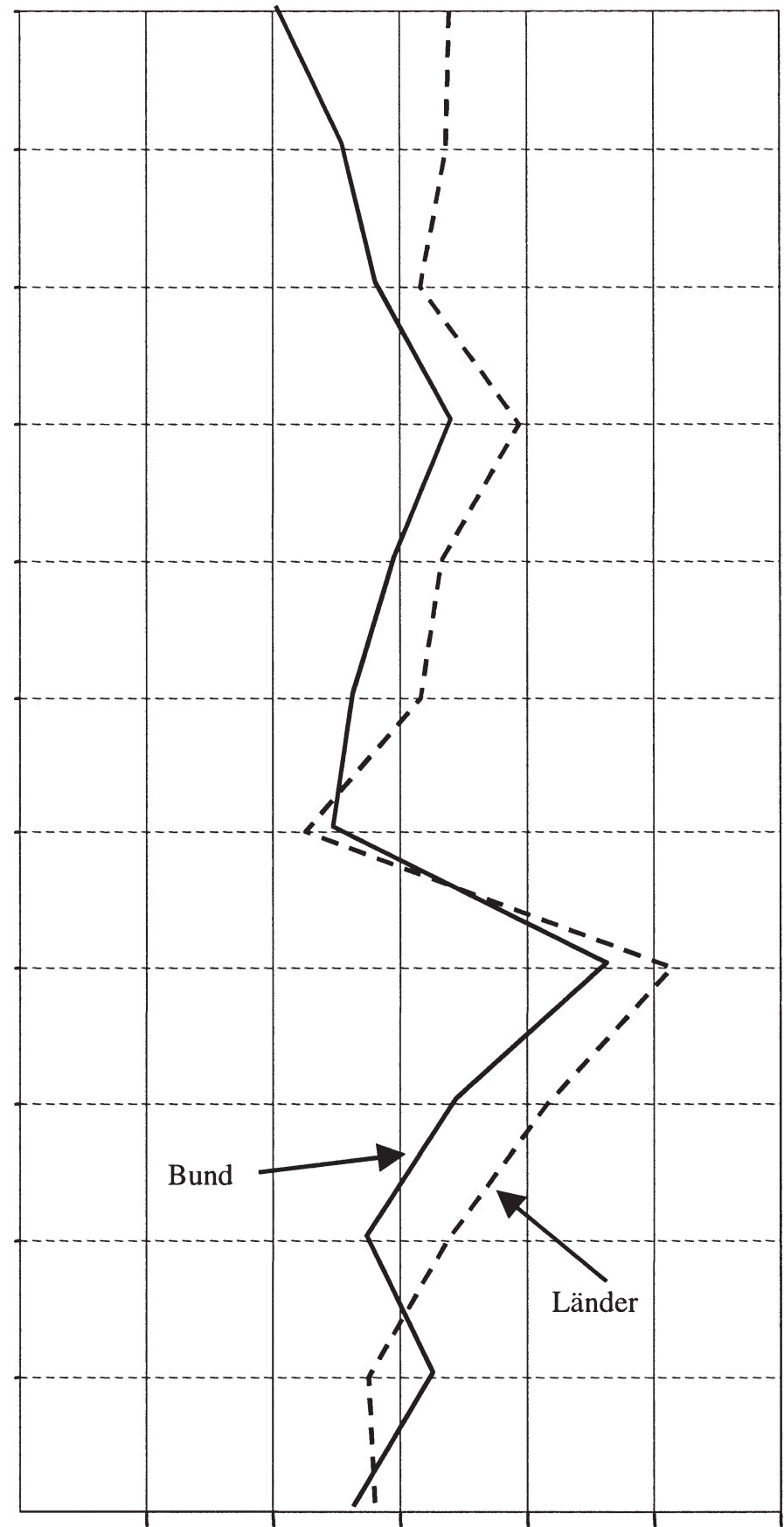

1

2
4
5
6
7

Fig. 11. Policy makers' perceptions of science

there is also a growing tendency for some scientists to deconstruct political facts to suit the needs of scientists as some of the evidence might suggest. This too is not necessarily a new insight, but it is a dangerous situation. Under such circumstances both politics and sci- ence are at an increased risk of losing their remaining levels of credibility and doing so at the expense of human well being.

Perhaps the data suggests science might be being driven by the needs of policy relevance, while policy 
How would you describe the working relationship between science and policy: $1=$ very good $7=$ very poor

Scientists are aware of policy makers information needs:

$1=$ very aware $7=$ very unaware

Science is instrumental in causing policy makers to redefine perceptions of GW issues: $1=$ very much $7=$ not at all

Policy makers draw on state of art knowledge: $1=$ always $7=$ never

Research is shaped by politics: $1=$ very much $7=$ not at all

Scientists control the transfer of information: $1=$ a great deal $7=$ not at all

Policy makers are influential in causing scientists to redefine perceptions of GW: $1=$ a great degree $7=$ not at all

There is growing pressure for science to be policy relevant: $1=$ a great degree $7=$ none at all

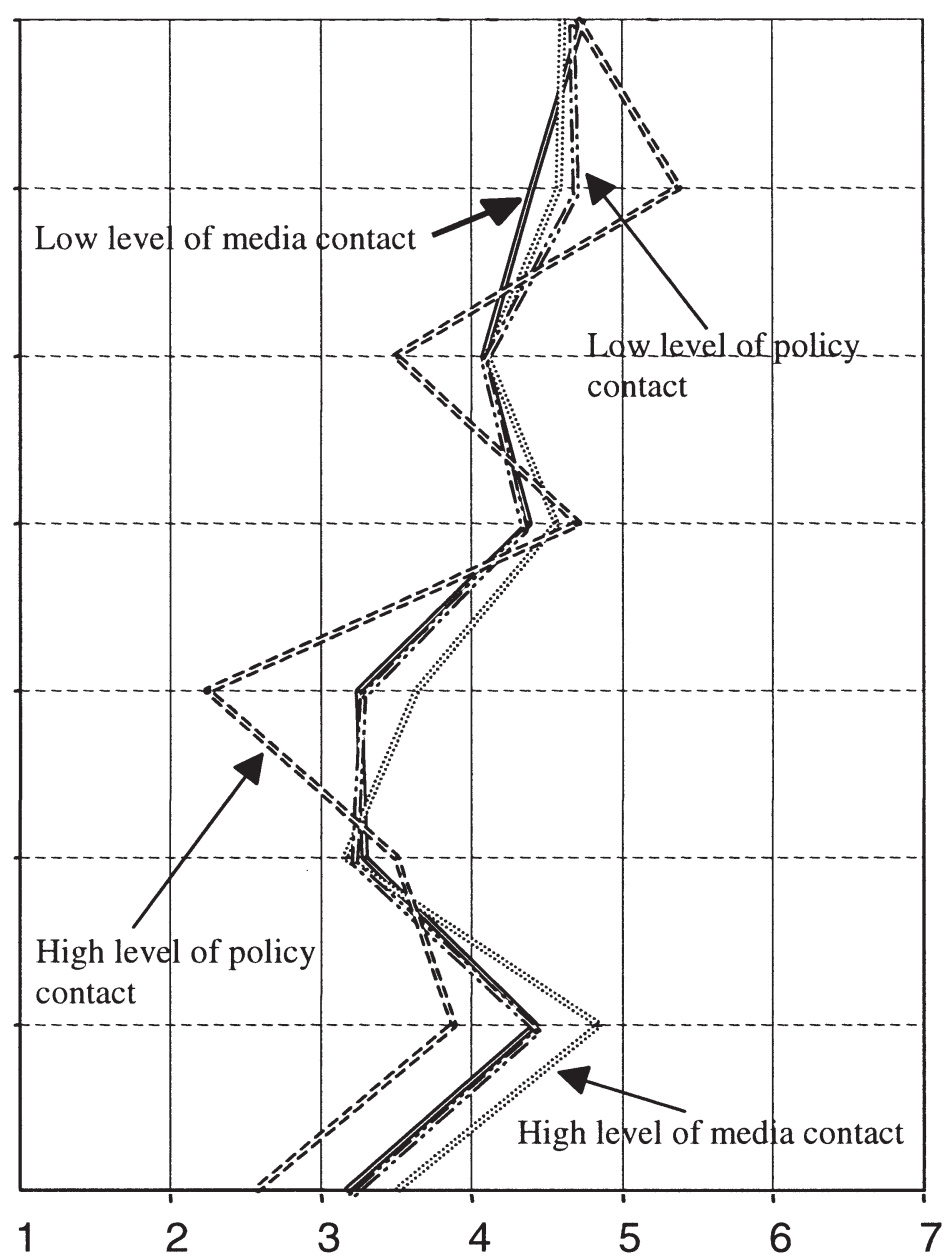

Fig. 12. Scientists' perceptions of the interaction with policy

makers are being pushed by forces external to science. In short, the scientific issue is 'released', becomes a monster via the public media, feeds back into politics and subsequently back into science. Since the scientists in this discussion claim that politics can change the scientists' perception of the issue (it is not clear in what direction) the opportunity exists for the increased role of normative judgments. One has to ask if climate science, as somewhat encased in green ideology and political aspirations, is perhaps at risk of becoming yet another example of regime-driven science. (This is not to indicate that we as authors of this paper disagree that the environment is indeed in great need of attention. On the contrary, many of the practices of contemporary society are in need of scrutiny in this regard.) Radical environmentalism - the green-extreme-is a moral philosophy and the marriage of moral philosophy, science and politics has in the past sometimes given birth to some less than desirable offspring. Many of the links and motivations in the current situation remain unexplored.

Acknowledgements. D.B. wishes to acknowledge the support of the following: The Thyssen Stiftung, Germany, MaxPlanck-Institut für Meteorologie, Hamburg, Germany, and the GKSS Forschungszentrum, Geesthacht, Germany, for support that has enabled this project. The results of this study do not and are not necessarily intended to reflect any views of GKSS or VDI.

\section{LITERATURE CITED}

Arrow KJ, Parikh J, Pillet G, Grubbs M, Haites E, Hourcade JC, Parikh K, Yamin F (1996) Decision-making frameworks for addressing climate change. In: Bruce JP, Lee $\mathrm{H}_{\text {, }}$ Haites EF (eds) Climate change 1995: economic and social dimensions of climate change. Cambridge University Press, Cambridge, p 53-124 
Battinelli P, Bray D, von Storch H (1999) Il punto di vista delgi scienziati del clima sul Cambiamento Climatico Globale. La Comunita Scientifica Italiana, Sotto il patrocinio del Ministero dell'Ambiente

Borscher J, Dresen L, Elzinga A, Krück C and 5 others (1997) EU Project 'Climate Change Research and Its Integration Into Environmental Policy: Conditions for the Establishment of A European Climate Region (CIRCITERS).' Progress Report IWT Paper 18, Institut für Wissenschaftsund Technikforschung, Universität Bielefeld

Bray D, von Storch H (1997a) The climate change issue perspectives and interpretations. In: Hocevar A, Crepinsek Z, Kajfez-Bogataj L (eds) Proceedings of the 14th International Congress of Biometeorology, Vol 3. International Society of Biometeorology, Ljubljana, p 439-450

Bray D, von Storch H (1997b) Survey explores views of 400 climate scientists. UN Clim Change Bull Issue 14, 2nd Quarter, p 6-7

Bray D, von Storch H (1999a) Climate science: an empirical example of postnormal science. Bull Am Meteorol Soc 80(3):439-455

Bray D, von Storch H (1999b) Climate science and the transfer of knowledge to public and political realms, Chap 9. In: von Storch H, Flöser G (eds) Anthropogenic climate change. Springer-Verlag, Berlin, p 281-322

Covello V, McCallum B, Pavlova M (eds) (1989) Effective risk communication, contemporary issues. Plenum, New York
Funtowicz S, Ravetz J (1985) Three types of risk assessment: a methodological analysis. In: Whipple C, Covello V (eds) Risk analysis in the private sector. Plenum, New York, p 831-848

Funtowicz S, Ravetz J (1990a) Uncertainty and quality in science for policy. Kluwer, Dordrecht

Funtowicz S, Ravetz J (1990b) Post-normal science: a new science for new times. Sci Eur 169:20-22

Grove-White R (1998) Risk society, politics and BSE. In: Franklin J (ed) The politics of risk society. Polity Press, Cambridge, p 9-22

Krück C, Bray D (2000) Wie schätzt die deutsche Exekutive die Gefahr eines globalen Klimawandels ein? Eine Meinungsumfrage zum Risikomanagement in der Umweltpolitik, GKSS Forschungszentrum, Geesthacht

Sarewitz D, Pielke R Jr (2000) Breaking the global-warming gridlock. The Atlantic online; available at: www. theatlantic.com/issues/2000/07/sarewitz.htm

von Storch H, Bray D (1999) Perspectives of climate scientists on global climate change. Conference Proceedings, Climate Change Policy in Germany and the United States, Berlin, the German-American Academic Council, June 15-18, 1997. Publ GAAC 7:33-48

von Storch H, Walløe Hansen A, Bray D (1999) En meningsmåling blandt danske klimaforskere om deres anskuelser med hensyn til globale klimaforandringer og dens betydning for politik og samfund. Vejret 79:39-44

Submitted: August 28, 2000; Accepted: May 11, 2001

Proofs received from author(s): September 7, 2001
Editorial responsibility: Hans von Storch, Geesthacht, Germany 